\title{
Reforma da Previdência: sustentabilidade e justiça atuarial
}

\author{
Reynaldo Fernandes ${ }^{1}$ \\ Naercio Menezes-Filho ${ }^{2}$ \\ André Portela Souza ${ }^{3}$ \\ Bruno Komatsu ${ }^{4}$ \\ Gustavo Marcos Mentlik ${ }^{5}$
}

\section{Resumo}

O artigo analisa a proposta de reforma da previdência social feita pelo governo Temer. Investigamos a sustentabilidade financeira do sistema proposto e a sua justiça atuarial. Consideramos as regras contidas na proposta original do governo. Procuramos dar respostas a duas questões relacionadas: (i) qual deveria ser a alíquota de contribuição para a previdência para que a proposta fosse equilibrada financeiramente?; e (ii) qual a taxa interna de retorno implícita da proposta Temer? Para tanto, desenvolvemos um modelo atuarial que é simulado para a geração que tem 25 anos de idade em 2015 com base na PNAD. A sustentabilidade financeira do novo sistema é muito sensível ao crescimento da produtividade e da taxa de formalização da economia. Admitindo as taxas atuais de formalização e um crescimento da produtividade de $2 \%$ a.a., a alíquota de equilíbrio para o agente representativo seria maior do que a alíquota proposta de $28 \%$. No entanto, a taxa de retorno implícita para o agente representativo é ao redor de $3 \%$, que é significativamente inferior à média das taxas básicas de juros que vigorou na economia brasileira nas últimas décadas.

1 Professor - Faculdade de Economia, Administração e Contabilidade de Ribeirão Preto - Universidade de São Paulo - End.: Av. Bandeirantes, 3900 - Monte Alegre - Ribeirão Preto/SP - CEP 14040-905 E-mail: refernan@usp.br - ORCiD: https://orcid.org/0000-0002-9305-4336

2 Professor - Insper Instituto de Ensino e Pesquisa e Faculdade de Economia, Administração e Contabilidade - Universidade de São Paulo - End.: Rua Quatá, 300 - Vila Olímpia - São Paulo/SP. CEP: 04546-042 - E-mail: naercioamf@insper.edu.br - ORCiD: https://orcid.org/0000-0003-1241-6188

3 Professor - Escola de Economia de São Paulo, Fundação Getúlio Vargas End.: Rua Itapeva, 474 Bela Vista/SP - CEP 01332-000 - E-mail: andré.portela.souza@fgv.br ORCiD: https://orcid.org/0000-0002-5988-2437

4 Pesquisador - Insper Instituto de Ensino e Pesquisa - Endereço: Rua Quatá, 300 - Vila Olímpia/SP. CEP: 04546-042 - E-mail: brunokk@uol.com.br - ORCiD: https://orcid.org/0000-0002-7731-3422

5 Graduado em Economia - Faculdade de Economia, Administração e Contabilidade, Universidade de São Paulo - Endereço: Av. Prof. Luciano Gualberto, 908 - Butantã - São Paulo/SP - CEP 05508-010. E-mail: Gustavo.mentilik@gmail.com - ORCiD: https://orcid.org/0000-0001-9596-8986 Recebido: 08/05/2018. Aceite: 28/02/2019. 


\title{
Palavras-Chave
}

Previdência social. Reforma previdenciária. Idosos. Justiça atuarial.

\begin{abstract}
The article analyzes the proposal of social security reform made by the Temer administration. We investigate the financial sustainability of the proposal and its actuarial justice. We consider the rules contained in the original proposal. We try to answer two related questions: (i) what should be the contribution aliquot for the proposal to be financially balanced? and (ii) what is the implicit internal rate of return of the Temer proposal? For that, we developed an actuarial model that is simulated for the generation with 25 years of age in 2015 based on the PNAD. The financial sustainability of the proposal is very sensitive to productivity growth and the formalization rate of the economy. Assuming the current rates of formalization and productivity growth of $2 \%$ per year, the equilibrium aliquot for the representative agent would be higher than the proposed rate of $28 \%$. However, the implicit rate of return for the representative agent is around $3 \%$, which is significantly lower than the average of the basic interest rates in the Brazilian economy in the last decades.
\end{abstract}

\section{Keywords}

Social security. Pension reform. Elderly. Actuarial justice.

\section{JEL Classification}

H55. J14.

\section{Introdução}

$\mathrm{Na}$ literatura sobre a sustentabilidade de aposentadorias e pensões, é razoavelmente consensual que o envelhecimento da população requer revisões das regras de funcionamento desses sistemas (Cf. inter alia, Tafner 2011; Nery 2016; Lima e Matias-Pereira 2014; Constanzi e Anciliero 2017; Andrade 2001; Afonso 2018). Uma vez que os benefícios previdenciários atingem principalmente os mais idosos, o aumento da proporção desse grupo na população tem levado diversos países cujos sistemas de previdência social operam sob o regime de repartição simples a rever suas regras (Tafner 2011; Giambiagi, Sidone 2018). Nesses sistemas, ceteris paribus, a redução do número de trabalhadores ativos e que financiam a parcela de aposentados ou pensionistas requer ou uma redução do benefício dos aposentados e pensionistas (em relação ao salário dos ativos) ou um aumento das alíquotas de contribuição dos ativos, para que o equilíbrio financeiro do sistema seja mantido. Essa tendência de envelhecimento da população 
ocorre também no Brasil (Giambiagi, Tafner 2010; Tafner 2012; Constanzi 2017) e tem sido documentada em trabalhos sobre demografia ao menos desde o início dos anos 2000 (Moreira 2001; Camarano 2002; Beltrão, Camarano, Canso 2004).

Além do fator demográfico, no entanto, os desequilíbrios ficais dos regimes de previdência social possuem raízes antigas, relacionadas à ausência de limitações de cobertura dos benefícios da previdência social. Os desequilíbrios fiscais gerados por essa combinação de fatores motivaram as duas reformas da previdência ocorridas desde a Constituição Federal de 1988, em 1998 e em 2003, e cujas alterações na legislação, contudo, foram insuficientes para corrigir os déficits do sistema (Zylberstajn, Afonso, Souza 2006).

Novamente com foco no seu equilíbrio financeiro de longo prazo, em dezembro de 2016 o governo de Michel Temer lançou uma Proposta de Emenda à Constituição (PEC 287/2016), que propunha alterações diversas em parâmetros fundamentais do Sistema de Previdência Social (Alegretti et al. 2016). Trata-se da proposta de reforma mais abrangente dos últimos anos (Afonso 2018), e que gerou intensas controvérsias no debate público e resistências no Congresso Nacional, com preocupações em torno da necessidade de equilibrar as contas públicas no longo prazo, e em relação à redução de direitos e benefícios sociais. ${ }^{1}$

Assim como no início dos anos 2000 (Zylberstajn, Afonso, Souza 2006), a proposta de reforma da previdência social de 2016 estava sendo vista como elemento necessário para a retomada do crescimento econômico ${ }^{2}$ e sua função de balanceamento das contas públicas foi colocada ainda mais em evidência após a aprovação da Emenda à Constituição no 95 de 2016, que impunha uma limitação aos gastos reais, a partir de 2017, dos Três Poderes, do Ministério Público e da Defensoria Pública no nível da União (Afonso 2018).

Neste artigo, analisamos a Proposta de Emenda Constitucional (PEC) $n^{\circ} 287$ de 2016, que traz propostas de alterações para o funcionamento do Sistema de Previdência Social no Brasil. Nossa principal contribuição é

1 Diversos artigos de jornal noticiam esses fatos, por exemplo, Benites e Mendonça (2017), El País (2017) e Shreiber (2017). Nery (2016) trata da questão da dificuldade de se aprovar uma reforma previdenciária como um problema de ação coletiva.

2 Essa posição foi expressa, por exemplo, em entrevista do então Ministro da Fazenda (BRASIL 2017a), e pelo líder do governo na Câmara dos Deputados (BRASIL 2017b). 
de avaliar, além da sustentabilidade financeira no longo prazo, aspectos da justiça atuarial que prevaleceriam caso a PEC fosse aprovada. Entendemos como justiça atuarial a situação em que, do ponto de vista ex-ante, o valor presente do fluxo de contribuições para o sistema ao longo do tempo se iguala, em média, ao valor presente do fluxo de benefícios previdenciários (Queisser, Whitehouse 2006). Para isso, desenvolvemos um modelo atuarial com base nas regras propostas na PEC e em dados empíricos obtidos da Pesquisa Nacional por Amostra de Domicílios (PNAD), procurando responder a duas questões centrais: (i) qual deveria ser a taxa de contribuição para a previdência sobre os salários (alíquotas) para que a proposta do governo Temer fosse equilibrada financeiramente e atuarialmente justa?; e (ii) qual a taxa interna de retorno ou taxa de juros implícita da proposta Temer? Nós calculamos as alíquotas atuarialmente justas e a taxa de retorno que prevaleceria sob a PEC para a geração que tem 25 anos de idade em 2015, sem considerar regras de transição e observando a idade de entrada no mercado de trabalho, a proporção de tempo que as pessoas contribuem para a previdência e a progressão dos salários no ciclo de vida. Levamos em conta ainda as pensões e a probabilidade de aposentadoria por invalidez.

Nossos resultados indicam que, se aprovado o novo sistema, sua sustentabilidade seria muito sensível ao crescimento da produtividade da economia e ao seu grau de formalização. A taxa de contribuição necessária para sustentar o sistema quando os indivíduos médios contribuem por 25 anos e o crescimento da produtividade é de $2 \%$ ao ano ficaria em pouco mais de 30\%. Mesmo com um crescimento real expressivo da produtividade brasileira de $3 \%$ ao ano, ${ }^{3}$ uma taxa de $28 \%$ não seria sustentável, pois a alíquota para as mulheres seria de $32 \%$. Isso, porém não significa necessariamente que as taxas de retorno sejam elevadas demais. A taxa de retorno implícita considerando o crescimento real da produtividade em $2 \%$ e alíquota de contribuição em $28 \%$ seria de no máximo $3 \%$ para o agente representativo, valor significativamente inferior à média das taxas básicas de juros que vigoraram na economia brasileira nas últimas décadas (Omar 2008; Bastos 2017). Por último, do ponto de vista da distribuição, apesar de ter sido vista inicialmente como uma reforma excessivamente dura (Afonso 2018), a PEC manteria o caráter redistributivo do nosso sistema de repartição atual. ${ }^{4}$

3 Cavalcante e De Negri (2014) calculam uma taxa de crescimento anual média da produtividade do trabalho de $1.1 \%$ entre 1992 e 2001 e de $1.85 \%$ entre 2001 e 2011.

4 Afonso e Fernandes (2005) analisam o fluxo de contribuição e benefícios da previdência social, ao longo do ciclo de vida, para 960 grupos de trabalhadores, formados por 3 grupos de educação, 4 grupos de região de residência e 80 coortes (os nascidos entre 1920 e 2000). Eles calculam a taxa interna 
O artigo procura trazer subsídios para o debate sobre a PEC n ${ }^{\circ} 287 / 2016$. Apesar de ter sido abandonada pelo governo ao final de 2017, após sofrer várias alterações no Congresso (Lyra, Azevedo 2017), ${ }^{5}$ a expectativa é de que a discussão em torno da PEC seja retomada após as eleições ou no início do próximo governo. Independentemente de quem vença a eleição presidencial de 2018, o problema da previdência e do equilíbrio das contas públicas não foi resolvido e a ausência de medidas apropriadas provavelmente levará a problemas de sustentabilidade das contas públicas (Queiroz, Figoli 2011) ou poderá tornar muito difícil respeitar o limite de teto de gastos públicos (Giambiagi, Pinto, Rothmuller 2018).

Este artigo também dialoga com a literatura sobre aspectos distributivos e de justiça social dos sistemas de previdência social. A literatura empírica que avalia os impactos das reformas implementadas no Brasil se divide entre trabalhos que analisam a sustentabilidade financeira dos sistemas e estudos que avaliam questões distributivas e de justiça social (Zylberstajn, Afonso, Souza 2006). Em relação ao primeiro ponto, o critério requerido é de que nos sistemas previdenciários por repartição as contribuições correntes dos ativos devem corresponder ao total das despesas correntes em benefícios dos inativos. Com esse objetivo, Afonso (2018) estima impactos fiscais da PEC sobre o Regime Geral de Previdência Social (RGPS), focando sobre seus resultados financeiros. Em relação ao segundo conjunto de estudos, um dos principais critérios é o de justiça atuarial, ou seja, se o valor presente das contribuições esperadas de cada indivíduo é igual ao valor presente dos seus benefícios esperados, de modo que não há redistribuição a partir ou para qualquer indivíduo. ${ }^{6}$ Este artigo avalia se a PEC é financeiramente sustentável, em um cenário em que há justiça atuarial, ou seja, em um cenário em que cada indivíduo recebe em benefícios aquilo que contribuiu.

de retorno (TIR) para cada um desses grupos e mostram que as TIRs são significativamente mais elevadas para os grupos mais vulneráveis (menor escolaridade e residentes da região norte, nordeste e centro-oeste), além de crescerem para as gerações mais novas.

5 As diversas alterações em relação à PEC original colocadas na Emenda Aglutinativa Global à Proposta de Emenda à Constituição no ${ }^{\circ}$ 287-A não serão analisadas nesse artigo. Como as alterações no geral visam reduzir as diferenças entre os benefícios atuais e aqueles que estariam vigentes caso a PEC fosse aprovada integralmente, a PEC original representa o caso com as maiores mudanças. Dessa forma, as alterações à $\mathrm{PEC}$ representam casos em que as exigências para o recebimento do benefício seriam menores, de modo que seria menos difícil manter a sustentabilidade financeira sob o critério de justiça atuarial.

6 O conceito de justiça atuarial não pode ser confundido com o de neutralidade atuarial. Apesar de ambos serem conceitos ex-ante, a neutralidade atuarial é um conceito marginal, usado para avaliar os incentivos de se aposentar em um dado momento no tempo e não um ano antes ou depois (Queisser, Whitehouse 2006). Neste artigo, não utilizaremos o critério de neutralidade atuarial em nossa avaliação. 
Apesar da importância das regras de transição, optamos por não incorporar a análise da transição ao artigo, uma vez que nosso foco é sobre o funcionamento do sistema de previdência no longo prazo. Os parâmetros estimados que utilizamos para nossas simulações foram pensados para a geração que possui 25 anos em 2015, que não estaria incluída na regra de transição contida na PEC, caso ela seja aprovada nesse ou em poucos anos. Com esse objetivo, utilizamos um modelo atuarial construído para análise de equilíbrios de estado estacionário no longo prazo e, por esse motivo, não é adequado para avaliar períodos de transição.

Em relação ao debate mais amplo sobre reformas de sistemas previdenciários, entre os especialistas que concordam que reformas são necessárias no Brasil, a discussão está em se realizar reformas paramétricas ou estruturais (Giambiagi, Sidone 2018; Turra, Afonso 2017), incluindo o cálculo de custos de transição entre o cenário vigente e aquele após a reforma. As reformas estruturais são aquelas em que se propõem modificar o sistema atual de repartição para o de capitalização, ou híbrido de capitalização e repartição (por exemplo, Zylberstajn, Afonso e Souza (2006), Zylberstajn et al. (2010)). Alguns autores argumentam que reformas desse tipo podem não ser a melhor solução, mesmo que gerem maiores taxas de retorno (Sinn 2000), ou podem gerar custos de transição elevados demais no curto ou médio prazos, de modo que sua aprovação no processo político não é factível (Giambiagi, Sidone 2018). Reformas paramétricas, em contraste, são aquelas em que se mantém a estrutura do sistema de repartição e se modificam alguns parâmetros do sistema (por exemplo, Zylberstajn, Afonso e Souza (2006), Giambiagi et al. (2007)). Apesar de não contribuirmos diretamente para esse debate, a análise traz subsídios para a discussão entre as opções de sistemas, uma vez que utilizamos o critério de justiça atuarial, que é atendido por construção nos sistemas de capitalização, como régua para medir a reforma paramétrica contida na PEC 287/2016.

Por último, este artigo também traz subsídios para o debate sobre a generosidade do sistema de previdência brasileiro. Com certa frequência, no debate público, o total de gastos com benefícios do INSS (como proporção do PIB) é comparado com o total dos gastos previdenciários em outros países, como forma de evidenciar o desajuste do sistema previdenciário brasileiro. ${ }^{7}$ Esse dado é mostrado nas duas últimas colunas da Tabela 1. Entre os países selecionados, o Brasil se encontra em posição intermediária (10 entre 18) nos gastos públicos com previdência, mesmo sendo um dos mais jovens,

${ }^{7}$ Por exemplo, Shreiber (2017). 
o segundo com o menor percentual de pessoas com 65 anos ou mais. No entanto, esse argumento deixa de levar em consideração as alíquotas de contribuição. Conforme se observa na Tabela 1, as alíquotas de contribuição são relativamente elevadas no Brasil. Na maioria dos demais países, as taxas de contribuições incidem apenas sobre o valor do salário que corresponde ao teto de contribuição (e benefício) (Goudswaard, Caminada 2015). No caso brasileiro, para os empregos formais do setor privado as alíquotas são de $20 \%$ para o empregador e de 8 a $11 \%$ para o trabalhador. Enquanto a contribuição dos empregados se dá até o teto dos benefícios pagos pelo Instituto Nacional do Seguro Social (INSS), a contribuição dos empregadores se dá sobre o total da folha de pagamentos.

Tabela 1 - Sistema de Previdência Social - Comparações Internacionais

\begin{tabular}{|c|c|c|c|c|c|c|}
\hline \multirow{2}{*}{ País } & \multirow{2}{*}{$\begin{array}{l}\text { Ano da } \\
\text { Alíquota }\end{array}$} & \multicolumn{3}{|c|}{ Alíquota de Contribuição } & \multirow{2}{*}{$\begin{array}{c}\text { Gasto Público } \\
\text { em Previdência } \\
(\% \mathrm{PIB})\end{array}$} & \multirow{2}{*}{$\begin{array}{c}\text { \% População } \\
\text { com } 65 \text { anos } \\
\text { ou mais }\end{array}$} \\
\hline & & Trabalhador & Empregador & Total & & \\
\hline Áustria & 2014 & 10,25 & 12,55 & 22,80 & 13.2 & $18.8 \%$ \\
\hline Bélgica & 2014 & 7,50 & 8,86 & 16,36 & 10.2 & $18.1 \%$ \\
\hline Canadá & 2013 & 4,95 & 4,95 & 9,9 & 4.3 & $16.1 \%$ \\
\hline Chile & 2013 & 10,0 & 1,26 & 11,26 & 3.2 & $10.4 \%$ \\
\hline França & 2014 & 10,05 & 14,70 & 24,75 & 13.8 & $18.9 \%$ \\
\hline Alemanha & 2014 & 9,45 & 9,45 & 18,90 & 10.6 & $21.1 \%$ \\
\hline Grécia & 2014 & 6,67 & 13,33 & 20,0 & 14.5 & $19.9 \%$ \\
\hline Irlanda & 2014 & 4,0 & 4,25 & 8,25 & 5.3 & $13.2 \%$ \\
\hline Itália & 2014 & 9,19 & 23,81 & 33,0 & 15.8 & $22.4 \%$ \\
\hline México & 2013 & 1,75 & 6,9 & 8,65 & 1.7 & $6.5 \%$ \\
\hline Holanda & 2014 & 18,5 & 5,7 & 24,2 & 5.5 & $17.9 \%$ \\
\hline Portugal & 2014 & 11,0 & 23,75 & 34,75 & 13.0 & $20.7 \%$ \\
\hline Espanha & 2014 & 4,7 & 23,6 & 28,3 & 10.5 & $18.9 \%$ \\
\hline Suécia & 2014 & 7,0 & 15,73 & 22,73 & 7.4 & $19.6 \%$ \\
\hline Reino Unido & 2014 & 9,05 & 11,90 & 20,95 & 7.6 & $18.1 \%$ \\
\hline Estados Unidos & 2013 & 6,2 & 6,2 & 12,4 & 6.7 & $14.6 \%$ \\
\hline Japão & 2014 & 8,737 & 8,737 & 17,474 & 10.2 & $26.0 \%$ \\
\hline Brasil & 2016 & 8,0 a 11,0 & 20,0 & 28,0 a 31,0 & 9.6 & $8.0 \%$ \\
\hline
\end{tabular}

Fonte: Dados de alíquotas obtidas de Goudswaard e Caminada (2015), com exceção dos dados para o Brasil. Dados de gastos públicos em previdência obtidos da base de dados World Bank Pension Database, atualizados para anos entre 2013 e 2015. Dados de população referentes a 2015, obtidos da base World Development Indicators, do Banco Mundial. 
Uma questão que os dados da Tabela 1 levanta é a seguinte: por que as elevadas alíquotas do INSS não são suficientes para equilibrar o sistema? Nossos exercícios mostram que, ao menos em parte, a questão é respondida pela elevada taxa de informalidade da mão de obra no Brasil. Uma parcela significativa da força de trabalho passa a maior parte do tempo de sua vida ativa como não contribuinte e, ainda assim, consegue se aposentar com o tempo mínimo de contribuição, que hoje é de 15 anos. ${ }^{8}$

Além desta introdução, descrevemos brevemente a proposta de reforma previdenciária na seção 2 . A seção 3 apresenta o modelo atuarial que utilizamos para construir nossas simulações, enquanto na seção 4 detalhamos a forma como incorporamos algumas das regras de aposentadoria e como estimamos empiricamente os parâmetros utilizados. A seção 5 traz os resultados das simulações e, por fim, na seção 6 serão apresentadas algumas conclusões.

\section{A Proposta de Reforma da Previdência (versão original)}

Nesta seção, detalhamos os aspectos mais relevantes da PEC 287/2016 para a nossa análise. ${ }^{9}$

A PEC 287/2016 determina que a aposentadoria passe a ter idade mínima de 65 anos para todos os contribuintes, incluindo mulheres e trabalhadores rurais. O tempo mínimo de contribuição passa a ser de 25 anos (ao invés dos 15 atuais) - inclusive para os trabalhadores rurais, que atualmente não são obrigados a contribuir para o INSS. A PEC não define a alíquota de contribuição dos trabalhadores rurais, mas a ideia é que ela deveria ser diferenciada e relativamente baixa. O projeto prevê o fim das diferenças entre os regimes dos servidores públicos e o da previdência geral, e o fim das regras diferenciadas para professores da educação básica no último regime. A partir da Constituição Federal de 1988, o Brasil possui três sistemas que compõem a Previdência Social, cada um deles funcionando sob um modelo de financiamento. São eles: o Regime Geral de Previdência

8 A isso se somam os trabalhadores rurais que hoje conseguem se aposentar mesmo que não consigam comprovar qualquer contribuição ao sistema.

9 Para maiores detalhes e uma comparação entre as regras atuais, as regras propostas na PEC 287/2016 e as alterações colocadas pela Comissão Especial da Câmara dos Deputados, ver Constanzi et al. (2018). 
Social (RGPS), que abrange os trabalhadores empregados no setor privado, autônomos, domésticos, rurais e seguros facultativos, e que funciona sob o regime de repartição simples; os Regimes Próprios de Previdência Social (RPPS), que abrangem os servidores públicos dos três níveis da federação, são obrigatórios para o funcionalismo e administrados pelos governos; e os regimes de previdência complementar, que são optativos e administrados por fundos de pensão abertos ou fechados (Tafner 2011). Nossa análise focará sobre os trabalhadores abrangidos pela PEC, ou seja, que são abrangidos pelo RGPS ou pelo RPPS.

A proposta envolve uma regra de transição para homens com mais de 50 anos e mulheres com mais de 45 anos; eles poderiam se aposentar pelas regras atuais, mas pagando um pedágio de $50 \%$ sobre o tempo que faltasse para a aposentadoria. Por exemplo, um homem com 50 anos que tenha 34 anos de contribuição, precisaria contribuir por mais um ano pela regra antiga. Aplicando-se 50\% a mais, ele teria direito à aposentadoria após um ano e seis meses a mais de contribuição.

A idade mínima para os beneficiários do Benefício de Prestação Continuada (BPC) passaria de 65 para 70 anos. O reajuste desse tipo de benefício passaria a ser desvinculado do salário mínimo, sendo ajustado apenas pela inflação. $\mathrm{O}$ valor do benefício seria definido em lei. Atualmente, o BPC equivale a um salário mínimo.

O piso do valor do benefício continua sendo o salário mínimo. A fórmula de cálculo dos benefícios tanto no Regime Geral de Previdência Social (RGPS) quanto no regime próprio (servidores públicos) continuaria tomando como base a média dos salários de contribuição, mas deixaria de seguir a fórmula 85/95, que atualmente garante aposentadoria igual a $100 \%$ da média de seu salário de benefício para aqueles cuja soma da idade com o tempo de contribuição for de 85 anos para mulheres e 95 para os homens. Com a aprovação da PEC, seria aplicada uma taxa de $51 \%$ sobre a média histórica das contribuições, acrescentando-se um ponto percentual por ano contribuído. O sistema de cálculo proposto calcula a média de todos os salários de contribuição, não só dos $80 \%$ maiores, como ocorre hoje.

Assim, um contribuinte com 65 anos que tenha 28 anos de contribuição receberá $79 \%$ do total da média de contribuições $(51+28=79)$. Se contribuiu 30 anos (5 anos além dos 25 obrigatórios), vai ganhar cinco pontos percen- 
tuais e ficar com $81 \%$ da média de salário $(76+5)$. Para receber integralmente o benefício, esse segurado precisará somar 49 anos de contribuição.

A PEC propõe alterações nas regras de pensão por morte, colocando uma cota familiar de $50 \%$ sobre a totalidade dos proventos do contribuinte até o limite de benefícios do RGPS. Além da cota familiar, há cotas individuais de 10 pontos percentuais para cada dependente, até o valor máximo de $100 \%$. Esse montante total é dividido igualmente entre os dependentes, que para o RGPS são definidos pelo Artigo 16 da Lei no 8.213 de 1991, como "cônjuge, a companheira, o companheiro e o filho não emancipado, de qualquer condição, menor de 21 (vinte e um) anos ou inválido ou que tenha deficiência intelectual ou mental ou deficiência grave". Além dessa classe de beneficiários, há outras duas, que só podem receber a pensão caso não haja ninguém da classe anterior e haja demonstração de dependência econômica. A classe seguinte é dos pais, e, depois dela, a dos irmãos não emancipados, menores de 21 anos, ou inválidos, ou que tenham deficiência intelectual ou mental, ou deficiência grave. Para o RPPS, os beneficiários são definidos de forma similar, pelas Leis $n^{\circ} 13.135$ de 2015 e nº 8.112 de 1990.

Os benefícios da pensão por morte são não cumulativos com outras aposentadorias e pensões por morte. Além disso, as cotas individuais, uma vez cessadas as condições que definem a qualidade de dependente, não são revertidas aos demais beneficiários. Por último, em caso de morte de servidor ainda em atividade, as pensões são calculadas a partir do valor devido à aposentadoria por invalidez.

\section{O Modelo}

Nesta seção, desenvolvemos o modelo atuarial dos fluxos de contribuições e benefícios para a aposentadoria sob a PEC n ${ }^{\circ} 287 / 2016$, abrangendo os membros da força de trabalho.

Admite-se que o trabalhador ingressa no mercado de trabalho formal no período 0 e permaneça como contribuinte até o período $T$, a partir do qual inicia-se o pagamento dos benefícios (aposentadoria ou pensão). O salário inicial do trabalhador é dado por $W_{o}$, sendo que sua evolução temporal 
dependente de dois fatores: i) aumento da produtividade da economia ii) aumento particular de salário, decorrente da progressão na carreira (tempo de serviço). Assim, admite-se o salário no período té dado por:

$$
w_{t}=w_{0} e^{(h+g) t}
$$

onde,

$h=$ taxa de crescimento da produtividade da economia;

$g=$ taxa de crescimento salarial em virtude da progressão na carreira

O valor presente, em zero, do fluxo de contribuições do trabalhador é dado por:

$$
V P_{0}^{c}=\int_{0}^{T} \pi a w_{0} e^{(h+g) t} e^{-r t} d t
$$

onde,

$a=$ alíquota de contribuição

$r=$ taxa de juros

$\pi=$ probabilidade de contribuir para a previdência a cada instante de tempo

Definindo $F$ como a data que o pagamento dos benefícios termina, o valor presente, no período zero, do fluxo de benefícios é dado por:

$$
V P_{0}^{b}=\int_{T}^{F} p w_{T} e^{k(t-T)} e^{-r t} d t
$$

onde,

$p=$ parcela do salário em $T$ que define o benefício (taxa de reposição)

$k=$ taxa de crescimento dos benefícios

Em (3), se os benefícios acompanham o crescimento dos salários dos trabalhadores ativos temos que $k=h$. Caso os benefícios só sejam ajustados pela inflação, temos que $k=0$. A alíquota de contribuição atuarialmente justa é 
aquela que iguala o valor presente das contribuições ao valor presente dos benefícios, que é dada por (4).

$$
a=\frac{p e^{(h+g-k) T}}{\pi} \frac{h+g-r}{e^{(h+g-r) T}-1} \frac{e^{(k-r) F}-e^{(k-r) T}}{k-r}
$$

Neste ponto se faz necessário destacar o papel desempenhado pela taxa de juros. A alíquota atuarialmente justa é extremamente sensível ao valor arbitrado para a taxa de juros, quanto maior a taxa de juros, menor a alíquota. A princípio, sempre existiria uma taxa de juros que torne compatível qualquer plano de contribuições com qualquer plano de benefícios. Considerando que o sistema de previdência deveria ser desenhado para vigorar por um longo período de tempo, a taxa de juros utilizada deveria ser a taxa de juros de equilíbrio de longo prazo. Aquela que esperamos que seja a taxa de juros média dos próximos, digamos, 40 anos.

Evidentemente, não é fácil estipular que taxa seria essa. ${ }^{10}$ Uma alternativa seria fixar a alíquota de contribuição e encontrar a taxa de juros resultante, que é a taxa interna de retorno (TIR). De posse da TIR, podemos avaliar se o retorno que o sistema de previdência oferece aos seus segurados é razoável. Para encontrarmos a TIR, podemos reescrever (4) como:

$$
r=\frac{p e^{(h+g-k) T}}{\pi} \frac{h+g-r}{e^{(h+g-r) T}-1} \frac{e^{(k-r) T}-e^{(k-r) F}}{a}+k
$$

Em (4'), $r$ é escrito como um ponto fixo, de modo que a TIR pode ser obtida por iterações sucessivas de $r$. O resultado é obtido quando o $r$ aplicado no lado direito de (4') resulta nele mesmo.

Uma preocupação recorrente das reformas previdenciárias é a busca pelo equilíbrio financeiro: que as contribuições dos ativos sejam iguais às despesas com os inativos. A Equação (4) nos permite encontrar a alíquota de contribuição que equilibra o sistema financeiramente, a qual vamos denominar alíquota de equilíbrio.

Aaron (1966) foi o primeiro a observar que a taxa de retorno de um sistema de previdência sob o regime de repartição simples é dada pela soma do

${ }^{10}$ Esse é justamente o principal ponto de debate em relação ao tema da justiça atuarial (Queisser, Whitehouse 2006). 
crescimento da força de trabalho e do crescimento dos salários reais (ou produtividade do trabalho). Então, para obtermos a alíquota de equilíbrio temos que substituir $r$, em (4), por $h+n$, onde $n$ é a taxa de crescimento da força de trabalho. ${ }^{11}$ Isso equivale a dizer que, no equilíbrio de longo prazo, não haveria diferença entre a alíquota que equilibra o sistema e a alíquota atuarialmente justa se taxa de juros atende a "regra de ouro" do estoque de capital, a qual maximiza a trajetória do consumo per capita. ${ }^{12}$ A alíquota de equilíbrio é dada por (5), sendo $k=h$ ou $k=0$.

$$
a=\left(\frac{p(g-n) e^{(h+g-k) T}}{e^{(g-n) T}-1} \frac{e^{(k-h-n) F}-e^{(k-h-n) T}}{k-h-n}\right) / \pi
$$

Em suma, se a taxa de juros de longo prazo diferir de $h+n$, não será possível obtermos uma alíquota de contribuição que, ao mesmo tempo, equilibre o sistema financeiramente e seja atuarialmente justa. Se $r>h+n$, uma alíquota que seja atuarialmente justa promoverá um déficit financeiro de equilíbrio.

\section{Parametrização}

Neste artigo, a análise é focada em pessoas com 25 anos de idade em 2015. Escolhemos essa idade inicial considerando que, normalmente, uma pessoa com 25 anos de idade concluiu seu ciclo de escolarização, e provavelmente permanecerá com o mesmo nível de escolaridade até que se aposente. O ano de 2015 é o último da série da PNAD anual, que possui estimativas comparáveis durante um longo período, também utilizado como base para obter estimativas de longo prazo da taxa de crescimento salarial com idade e probabilidade de contribuição para a previdência, como veremos abaixo. ${ }^{13}$

\footnotetext{
${ }^{11}$ Uma demonstração dessa proposição é apresentada no Apêndice I.

12 Esta é, também, a taxa de juros de steady state que seria obtida numa economia competitiva e sem incerteza, em que a taxa de preferência intertemporal das famílias que menos descontam o futuro é zero e cujas famílias se preocupam com as futuras gerações da mesma forma que se preocupam com elas mesmas [ver Blanchard e Fischer (1989), cap.2 e 3].

${ }^{13}$ Apesar de microdados do RGPS representarem uma fonte de dados para estimativas mais precisas de alguns dos parâmetros do modelo (como faz Afonso (2018)), optamos por utilizar a base de dados da PNAD para as estimações, uma vez que permite a estimação de parâmetros incluindo a população de trabalhadores que não contribui para a previdência e está fora dos registros do INSS.
} 
As idades com que os indivíduos começam a contribuir para o INSS $\left(I_{0}\right)$ foram obtidas diretamente da PNAD de 2015, enquanto os valores de $n$, para homens e mulheres foram extraídos da Projeção da População do IBGE, de 2013. As taxas de crescimento da população foram calculadas com base em indivíduos de 25 a 65 anos, entre 2000 e 2060. ${ }^{14}$ Os valores de $g$ foram obtidos por meio das regressões mincerianas a partir da base de dados empilhada da PNAD entre 1992 e 2015, e que são apresentadas no Apêndice de resultados.

Os valores de $h$ foram definidos de forma exógena como $1 \%$, 2\% e 3\%.

Para a obtenção dos valores de $p$ adotou-se o procedimento que segue. O valor do benefício da aposentadoria na nova regra é definido como um percentual do salário médio de todo o período, sendo o valor de $p$ definido por $p=\frac{\tilde{p} \bar{w}}{w_{T}}$, onde $w_{T}$ é o último salário recebido, $\bar{w}$ é o salário médio do período de contribuição e $\tilde{p}$ é o percentual definido pela regra da aposentadoria, que é dada por $\tilde{p}=0.51+0.01 * \pi T, \forall \tilde{p} \leq 1$. Por exemplo, se um indivíduo trabalha dos 25 aos 65 anos sem parar, pela nova regra ele recebe 91\% do salário médio do período de contribuição.

Por definição e pela Equação (1), temos:

$$
\bar{w}=\frac{\int_{0}^{T} w_{t} d_{t}}{T}=\frac{\int_{0}^{T} w_{0} e^{(h+g) t} d_{t}}{T}
$$

Logo,

$$
p=\frac{\tilde{p}}{T(g+h)} \frac{\left[e^{(h+g) T}-1\right]}{e^{(h+g) T}}
$$

A Equação (7) vale para as situações em que o salário de contribuição é superior ao salário mínimo e produzirá um benefício também acima do salário mínimo, que são ajustados à taxa $k=0$. Para os indivíduos que tenham o valor de benefício inferior ao salário mínimo no momento da

\footnotetext{
${ }^{14}$ Por simplicidade, estamos trabalhando com uma taxa média de crescimento anual da população ativa entre 2000 e 2060. As tabelas do IBGE, no entanto, colocam projeções de crescimento dessa parcela da população até 2038, e decréscimo dessa data até 2060. Caso permitíssemos que a taxa de crescimento populacional variasse ao longo do tempo, as taxas de desconto seriam menores para as idades mais elevadas e maiores para as idades mais jovens. Nesse caso, em comparação com os nossos resultados, as alíquotas necessárias para fechar o sistema teriam que ser maiores para todos os indivíduos. Essa modificação, porém, não altera nossas conclusões qualitativas.
} 
aposentadoria, o benefício mínimo implementado é o salário mínimo (SM). Para isso, em primeiro lugar, calculamos o benefício que seria recebido pelos indivíduos representativos em $T$, usando os valores estimados da taxa de crescimento salarial devido à experiência $g$ e a taxa de crescimento da produtividade da economia $h$ :

$$
\tilde{p} \bar{w}=\tilde{p} \frac{\int_{0}^{T} w_{0} e^{(h+g) t} d_{t}}{T}=\tilde{p} w_{0} \frac{\left[e^{(h+g) T}-1\right]}{T(g+h)}
$$

O salário inicial $w_{0}$ foi calculado a partir da PNAD 2015 para indivíduos com 25 anos que contribuíam para a previdência. ${ }^{15} \mathrm{Em}$ seguida, comparamos esse valor ao salário mínimo que seria vigente em $T$, que é dado por $S M_{T}=S M_{0} e^{h T}$. Na prática, $S M_{T}$ foi obtido por se capitalizar o salário mínimo vigente em 2015, pela taxa $h$, entre 2015 e o período de início do pagamento dos benefícios $(T)$.

Para os indivíduos que devem receber como valor de benefício o salário mínimo, os benefícios crescem à taxa de produtividade da economia, $k=h$. Nesses casos, portanto, a equação da taxa de reposição que multiplica o salário no período da aposentadoria $(T)$ é: $p^{S M}=\frac{S M_{T}}{W_{T}}$. Há casos intermediários em que os indivíduos começam recebendo o valor médio das suas contribuições e, após algum tempo $(\Delta T)$, o salário mínimo alcança esse valor antes do período final. Nesse caso, computamos o valor presente do fluxo de benefícios somando o valor presente do fluxo com o valor médio das contribuições entre $T$ e $T+\Delta T$ e com o valor do salário mínimo e crescimento à taxa entre $T+\Delta T$ e $F^{16}$

A PEC $n^{\circ}$ 287/2016 estabelece o valor máximo para os benefícios das aposentadorias é o teto do RGPS (parágrafo $2^{\circ}$ do Artigo 40). Nos nossos exercícios, utilizamos a hipótese de que esse teto evolui à taxa $h$, a partir do valor estabelecido para 2015 , de $\mathrm{R} \$ 4.663,75$. $^{17}$

Os valores para $\pi$ foram estabelecidos de três formas distintas: (i) como uma proporção fixa de $100,00 \%$, (ii) como uma proporção que define

\footnotetext{
${ }^{15}$ A PNAD 2015 não dá o salário de ingresso ( $\left.w_{0}\right)$, uma vez que, de modo geral, os indivíduos ingressam no mercado de trabalho antes dos 25 anos. Entretanto, de posse de $g, h$ e do salário médio para cada um dos grupos de indivíduos com 25 anos de idade em 2015, obteve-se uma estimativa do salário inicial para o agente representativo de cada um dos grupos.

16 Uma descrição mais detalhada desse caso se encontra no Apêndice III.

${ }^{17}$ Valor obtido a partir da Portaria Interministerial no ${ }^{\circ}$, de 9 de janeiro de 2015.
} 
o tempo de contribuição mínimo (25 anos) e (iii) as probabilidades estimadas a partir das PNADs 1992-2015 para pessoas com idade entre a idade de ingresso no mercado de trabalho $\left(I_{0}\right)$ e 65 anos. Nas situações (ii) e (iii), os valores de $\pi$ variam entre grupos de escolaridade e sexo. $\mathrm{Na}$ situação (iii) considerou-se apenas os indivíduos que fazem parte da PEA: a probabilidade de ser contribuinte (formal) dado que faz parte da PEA. Nos casos em que a probabilidade de contribuição é baixa o suficiente para que o tempo de contribuição seja inferior ao limite mínimo de 25 anos, adotaram-se diferentes procedimentos que serão explicados na seção de resultados. $^{18}$

Os valores de $T$ incluem a probabilidade de os indivíduos se aposentarem por incapacidade permanente para o trabalho. Seguindo Fernandes e Narita (2003), o valor de $T$ é dado por:

$$
T=\left(1-p_{\text {inc }}\right)\left(\text { Idade }_{\text {ninc }}-I_{0}\right)+p_{\text {inc }} *\left(\text { Idade }_{\text {inc }}-I_{0}\right)
$$

$p_{\text {inc }}$ : a probabilidade de aposentadoria por incapacidade permanente para o trabalho (utilizamos a estimativa da probabilidade de aposentadoria por invalidez, de 0,1665).

Idade $_{\text {ninc }}$ : idade esperada de aposentadoria daqueles que não se aposentam por incapacidade para o trabalho. Em nossas simulações, fixamos o valor em 65 anos.

Idade $_{\text {inc: }}$ idade esperada de aposentadoria daqueles que se aposentam por incapacidade para o trabalho.

$I_{0}$ : idade em que a pessoa começa a trabalhar.

Os valores de variam conforme os grupos de sexo e região (urbano e rural) e foram retirados do Anuário Estatístico da Previdência Social (AEPS) 2015. Para os indivíduos da zona urbana, os valores são: 52,3 para os homens e 53,36 para as mulheres. Para aqueles de zona rural, 50,25 para os homens e 47,49 para as mulheres. As idades de aposentadoria daqueles que não se aposentam por invalidez foram obtidas com base na PNAD e de acordo com as regras impostas pela proposta de reforma. Para se estimar

\footnotetext{
${ }_{18}$ Note que para simplificar as equações das seções 4 e 5 , padronizamos o instante inicial de entrada no mercado de trabalho para zero, de modo que o instante de aposentadoria e o período de atividade coincidem e são denotados por $T$. Empiricamente, $T$ denota o período de contribuição e o instante de aposentadoria, caso o instante inicial fosse padronizado para zero.
} 
a probabilidade de aposentadoria por invalidez, utilizou-se a razão entre o fluxo anual de entrada na aposentadoria por invalidez e fluxo total de benefícios concedidos por idade, invalidez ou por tempo de contribuição, também obtidos com base no Anuário Estatístico da Previdência Social (AEPS) 2015. A idade em que a pessoa começou a trabalhar foi obtida a partir dos dados da PNAD 2015, entre as pessoas que estiveram ocupadas em algum momento no período de 1 ano antes da entrevista.

Os valores de $F$ foram calculados com base na idade de aposentadoria de 65 anos e nas Tábuas Completas de Mortalidade - 2015 (IBGE, 2016) ${ }^{19}$ e ajustados pela padronização em que o instante de entrada no mercado de trabalho é igual a zero. Além disso, fizemos mais um ajuste conforme Fernandes e Gremaud (2003) e Fernandes e Narita (2003), para incluir pensão por morte, somente nos casos de cônjuges e após o beneficiário se aposentar. ${ }^{20}$ Estamos também tratando as pensões como vitalícias, uma vez que entre os indivíduos médios que analisamos, a idade média do cônjuge é pouco inferior à idade do beneficiário. Dessa forma, quando ocorre a morte do beneficiário, a idade do cônjuge é superior ao limite mínimo de 44 anos para que a pensão seja vitalícia.

Para realizar o ajuste de $F$, a partir da PNAD 2015, computou-se a proporção daqueles que possuem cônjuge presente $\left(p_{\text {conj }}\right)$ para os indivíduos de 65 anos de idade. Em seguida, para os que possuem cônjuge presente, a idade média deste foi calculada e, com base nisso, seu tempo médio de sobrevida. Por simplicidade, aplicamos o percentual do benefício ao qual o cônjuge tinha direito pela regra de pensão por morte sobre o tempo de recebimento do benefício além da morte do beneficiário e não sobre o valor do benefício. Esse procedimento nos traz uma aproximação do valor do fluxo total de benefícios, em que se multiplicam os valores dos benefícios pelo tempo de recebimento. Como estamos supondo somente um dependente, pela regra, o percentual do benefício obtido é de $60 \%$, sendo $50 \%$ da cota familiar, mais 10 pontos percentuais relativos à cota individual. Definindo $S_{T}$ como o tempo esperado de sobrevida do indivíduo de 65 anos de idade e $S_{C}$ como o tempo de sobrevida do cônjuge, o tempo

${ }^{19}$ Apesar de haver diferenças significantes entre as taxas de mortalidade de acordo com as características individuais (Silva, Freire, Pereira 2016), não é do escopo do artigo estimar as taxas de sobrevida a partir daquelas. Diferenciamos as estimativas de sobrevida somente entre homens e mulheres.

${ }^{20}$ Caso o beneficiário não seja aposentado, a regra colocada pelo parágrafo 16 do Artigo 201 é de que os dependentes receberiam uma proporção do benefício ao qual o beneficiário teria direito caso se aposentasse por incapacidade permanente na data da morte. 
esperado da duração do benefício dos indivíduos que se aposentam em idade $T$ é determinado por:

$S=65-I_{0}+\max \left(S_{T}, S_{T}+\left[\left(65-\right.\right.\right.$ Idade $\left.\left.\left._{\text {Conj }}\right)+\left(S_{T}-S_{C}\right)\right] \times 0,6\right)$

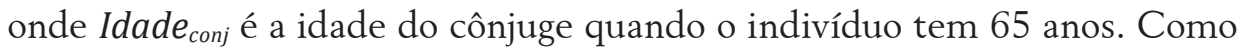
a idade do cônjuge só é inferior à do indivíduo no caso dos homens e a expectativa de sobrevida desses é menor em qualquer idade, somente eles gerarão pensões por morte entre os indivíduos médios investigados.

Os valores ajustados de $F\left(F_{a j}\right)$ foram então calculados utilizando a probabilidade de os indivíduos terem cônjuges $\left(p_{c o n j}\right)$ :

$$
F_{a j}=\left(1-p_{\text {conj }}\right) F+p_{\text {conj }} S
$$

A Tabela 2 abaixo mostra os parâmetros $n$ e $F_{a j}$ utilizados. Os trabalhadores urbanos foram separados por faixas de escolaridade, enquanto os trabalhadores rurais foram alocados em um grupo único. $\mathrm{O}$ agente representativo é o agregado geral para todas as pessoas.

Tabela 2 - Taxa de Crescimento Populacional e Idade Final

\begin{tabular}{lcccc}
\hline \multirow{2}{*}{ Grupos } & \multicolumn{4}{c}{ Parâmetros } \\
\cline { 2 - 5 } & \multicolumn{2}{c}{ Crescimento Pop. $(\boldsymbol{n})$} & \multicolumn{2}{c}{$\boldsymbol{F}_{\boldsymbol{a} \boldsymbol{j}}$} \\
\cline { 2 - 5 } & $0.587 \%$ & $0.642 \%$ & 68.14 & 69.65 \\
\hline Até EF1 & $0.587 \%$ & $0.642 \%$ & 68.32 & 70.20 \\
EF1 até EF2 completo & $0.587 \%$ & $0.642 \%$ & 68.07 & 69.71 \\
EF2 até EM completo & $0.587 \%$ & $0.642 \%$ & 66.83 & 67.90 \\
Acima de EM completo & $0.587 \%$ & $0.642 \%$ & 68.85 & 69.78 \\
Rural & $0.587 \%$ & $0.642 \%$ & 67.86 & 69.76 \\
Agente Representativo & &
\end{tabular}

É curioso notar que o tempo de recebimento dos benefícios é maior para os homens, apesar de os homens possuírem uma menor expectativa de vida. Isso porque os homens possuem, em média, cônjuges mais novos e, após a morte, os benefícios continuam sendo pagos ao cônjuge. Consideramos os benefícios como vitalícios, ou seja, até que o cônjuge, caso seja mais jovem, venha a falecer. Além disso, não consideramos o caso de pensão por morte antes das aposentadorias. 
Por fim, estimamos o coeficiente $g$ (taxa de crescimento salarial em virtude da progressão na carreira) a partir de uma regressão do logaritmo dos salários dos indivíduos de 25 a 65 anos de idade com dados das PNADs de 1992 a 2015. A regressão utilizada que determina o valor de $g$ é a seguinte: $\ln w=\alpha+\beta$ tempo de serviço $+d_{t}+\varepsilon$, em que tempo de serviço é definido como idade menos idade que começou a trabalhar e $d_{t}$ é o efeito fixo do ano $t$. O parâmetro $\beta$ identifica o valor de $g$. A regressão acima foi estimada separadamente para cada um dos grupos considerados e é mostrada nas tabelas do Apêndice II.

\section{Resultados}

\subsection{Equilíbrio Financeiro}

Num modelo de repartição simples, o equilíbrio financeiro do sistema define-se pela igualdade entre os valores das contribuições dos ativos e das despesas com os inativos. Como demonstrado no Apêndice I, a taxa de retorno desse sistema, para dados tempos de atividade $T$ e inatividade (entre $T$ e $F),{ }^{21}$ é dada pela soma da taxa de crescimento da produtividade $h$ e a taxa de crescimento populacional $n$. Se a taxa de juros de longo prazo da economia $r$ for igual à soma da taxa de crescimento da produtividade e a taxa de crescimento populacional $(r=h+n)$, o sistema de repartição simples será não apenas equilibrado financeiramente, mas também atuarialmente justo.

Iniciamos as simulações considerando o caso em que a taxa de juros utilizada para o cálculo do desconto intertemporal é igual à soma da taxa de crescimento da produtividade e a taxa de crescimento populacional. Portanto, o exercício trata de estimar as alíquotas necessárias para equilibrar financeiramente o sistema para um modelo de previdência de repartição simples conforme a proposta original do governo Temer. Nesse exercício calcula-se a alíquota necessária para o equilíbrio financeiro e a compara com a alíquota estabelecida pela proposta Temer. Se elas tiverem valores muito próximos, concluímos que a proposta Temer institui um sistema previdenciário equilibrado financeiramente.

${ }^{21} \mathrm{Na}$ descrição do modelo, na seção $4, T$ é o instante de aposentadoria, mas também é o período de atividade, uma vez que o instante inicial é padronizado para zero. 


\subsubsection{Agente representativo}

A primeira sequência de exercícios trata do caso do agente representativo, a mulher ou homem médio de 25 anos observado na PNAD de 2015. A Tabela 3 apresenta os valores das alíquotas para o agente representativo com a desagregação por sexo. Eles começam a trabalhar com idade $I_{0} \mathrm{e}$ permanecem trabalhando até os 65 anos, momento em que passam a receber benefícios de aposentadoria. As alíquotas ótimas são definidas para os casos em que os valores dos benefícios crescem à taxa de crescimento da economia $(h)$, quando o valor do benefício é igual ao salário mínimo, e para situações em que os benefícios crescem à taxa real zero, quando o valor do benefício é superior ao salário mínimo. Nos casos em que os indivíduos recebem o salário mínimo desde o início do período de aposentadoria, os valores das alíquotas estão em negrito.

As duas primeiras colunas da Tabela 3 mostram o caso em que se considera que os indivíduos contribuem durante todo o tempo em que estão no mercado de trabalho $(\pi=100 \%)$ e uma taxa de crescimento real dos benefícios nula $(k=0)$. Nesse caso, as alíquotas necessárias para o agente representativo da população ficam em $28 \%$ quando o crescimento médio da produtividade da economia $(h)$ é de $1 \%$ a.a. As alíquotas necessárias diminuem quando a taxa de crescimento da economia aumenta: para $h=2 \%$, elas ficam entre $21 \%$ e $22 \%$, e para $h=3 \%$, entre $19 \%$ e $21 \%$. Esses valores indicam, portanto, que as alíquotas estimadas pelo modelo são próximas ou inferiores àquelas praticadas atualmente no Regime Geral de Previdência Social (RGPS), no caso em que os indivíduos contribuem 100\% do tempo em que estão no mercado de trabalho.

Os valores das taxas de reposição diminuem conforme a taxa $h$ aumenta, uma vez que, com a nossa especificação, o salário médio $(\bar{w})$ aumenta menos do que o valor do último salário $\left(w_{T}\right)$. Quando $h$ aumenta de $1 \%$ para $2 \%$, o agente representativo feminino passa a receber o salário mínimo entre o instante da aposentadoria e o período final. Quando $h$ passa de $2 \%$ para $3 \%$, o mesmo ocorre para ambos os sexos.

Conforme a probabilidade de contribuição para a previdência $(\pi)$ diminui, as alíquotas necessárias aumentam, uma vez que o valor presente do fluxo de contribuição diminui. Considerando o valor intermediário da taxa de crescimento da produtividade $(h=2 \%)$ e ajustando $\pi$ para que os trabalhadores contribuam exatamente 25 anos, podemos observar nas colunas (3) 
e (4) que as alíquotas crescem mais de 10 pontos percentuais, chegando a $36 \%$ e $33 \%$, respectivamente para mulheres e homens.

O valor da alíquota em negrito faz referência à situação em que, pela regra do salário médio, o valor do benefício é inferior ao salário mínimo desde o início do período de aposentadoria. Quando isso ocorre, os valores dos benefícios são ajustados ao salário mínimo, que cresce à taxa $k=h$. Note que esse é o caso das mulheres na coluna (3), quando temos $h=3 \%$.

Tabela 3 - Alíquotas que Equilibram o Sistema para o Agente Representativo

\begin{tabular}{|c|c|c|c|c|c|c|c|c|}
\hline & \multicolumn{2}{|c|}{$\pi$ Fixo em $100 \%$} & \multicolumn{2}{|c|}{$T \pi$ Fixo em 25 anos } & \multicolumn{2}{|c|}{$\pi$ Estimado } & \multicolumn{2}{|c|}{$\begin{array}{c}\pi \text { Estimado, } \\
T \text { Ajustado }\end{array}$} \\
\hline & $\begin{array}{l}\text { Mulher } \\
\text { (1) }\end{array}$ & $\begin{array}{l}\text { Homem } \\
\text { (2) }\end{array}$ & $\begin{array}{c}\text { Mulher } \\
\text { (3) }\end{array}$ & $\begin{array}{c}\text { Homem } \\
\text { (4) }\end{array}$ & $\begin{array}{c}\text { Mulher } \\
\text { (5) }\end{array}$ & $\begin{array}{c}\text { Homem } \\
\text { (6) }\end{array}$ & $\begin{array}{c}\text { Mulher } \\
(7)\end{array}$ & $\begin{array}{c}\text { Homem } \\
\text { (8) }\end{array}$ \\
\hline Pr. Contribuiç̧ão $(\pi)$ & $100 \%$ & $100 \%$ & $54.1 \%$ & $53.1 \%$ & $47.6 \%$ & $51.1 \%$ & $47.6 \%$ & $51.1 \%$ \\
\hline Taxa de Cresc. Salarial $(g)$ & $1.14 \%$ & $1.81 \%$ & $1.14 \%$ & $1.81 \%$ & $1.14 \%$ & $1.81 \%$ & $1.14 \%$ & $1.81 \%$ \\
\hline Idade Inicial $\left(I_{0}\right)$ & 16.99 & 16.00 & 16.99 & 16.00 & 16.99 & 16.00 & 16.99 & 16.00 \\
\hline Idade de Aposentadoria & 65.0 & 65.0 & 65.0 & 65.0 & 65.0 & 65.0 & 72.4 & 67.2 \\
\hline Tempo de Contrib. $(T \pi)$ & 46.2 & 47.1 & 25.0 & 25.0 & 22.0 & 24.0 & 25.0 & 25.0 \\
\hline \% População & $51.1 \%$ & $48.9 \%$ & $51.1 \%$ & $48.9 \%$ & $51.1 \%$ & $48.9 \%$ & $51.1 \%$ & $48.9 \%$ \\
\hline \multicolumn{9}{|l|}{$h=1 \%$} \\
\hline$\alpha$ & 0.28 & 0.28 & 0.40 & 0.42 & - & - & 0.29 & 0.38 \\
\hline Taxa de Reposição & 0.62 & 0.54 & 0.48 & 0.42 & - & - & 0.46 & 0.41 \\
\hline \multicolumn{9}{|l|}{$h=2 \%$} \\
\hline$\alpha$ & 0.22 & 0.21 & 0.36 & 0.33 & - & - & 0.22 & 0.29 \\
\hline Taxa de Reposição & 0.51 & 0.46 & 0.40 & 0.35 & - & - & 0.37 & 0.34 \\
\hline \multicolumn{9}{|l|}{$h=3 \%$} \\
\hline$\alpha$ & 0.21 & 0.19 & 0.32 & 0.32 & $=$ & - & 0.20 & 0.28 \\
\hline Taxa de Reposição & 0.43 & 0.39 & 0.34 & 0.30 & $=$ & - & 0.31 & 0.29 \\
\hline
\end{tabular}

Nota: os valores em negrito representam casos em que o indivíduo recebe o valor do salário mínimo como benefício desde o início do período de aposentadoria.

Como mostram as colunas (5) e (6), caso consideremos os valores do tempo de contribuição $(\pi T)$ estimados pela $\operatorname{PNAD}(21,9$ anos para mulheres e 24 para homens), o agente representativo não poderia se aposentar aos 65 anos de idade. Note-se que nesses casos, consideramos que os indivíduos não alteram seu tempo de contribuição em função da mudança das regras. Eles se comportam como observamos na PNAD e, dessa forma, eles não obtêm o tempo mínimo de contribuição de 25 anos. 
Os resultados apresentados nas duas últimas colunas da Tabela 3 descrevem os valores das alíquotas necessárias considerando, para o caso em que os valores de $\pi$ são estimados pela PNAD, que os indivíduos podem se aposentar após os 65 anos. As simulações consideram a idade de aposentadoria necessária para que sejam obtidos 25 anos de contribuição, 72,4 anos para as mulheres e 67,2 anos para os homens. Considerando $h=2 \%$, as alíquotas necessárias seriam de $22 \%$ e $29 \%$, respectivamente para mulheres e homens.

Vale destacar que na maioria das simulações da Tabela 3 as alíquotas necessárias foram maiores para os homens do que para as mulheres. Isso porque o benefício dos homens tende a durar mais do que o das mulheres, apesar de os homens possuírem uma menor expectativa de vida. Os homens possuem, em média, cônjuges mais novos e, após a morte, os benefícios continuam sendo pagos ao cônjuge. Esse fato não ocorre para todos os casos, uma vez que os benefícios recebidos pelas mulheres nas colunas 1 e 2 passam a ser o piso salarial em algum momento entre a aposentadoria e o instante final. As alíquotas nesses casos são elevadas pelo crescimento do salário mínimo.

\subsubsection{Grupos Sociodemográficos}

Também fizemos os mesmos exercícios para grupos sociodemográficos separadamente. A Tabela 4 apresenta os valores das alíquotas necessárias para indivíduos urbanos médios por grupos de sexo e escolaridade, e para indivíduos rurais por grupos de sexo, considerando que eles contribuem $100 \%$ do tempo em que permanecem no mercado de trabalho. A distribuição da população entre os grupos utilizados no modelo é apresentada na tabela. Esses valores foram definidos tendo como base indivíduos de 25 anos, pela PNAD 2015. Nota-se que 35\% da população possui grau de educação entre o Ensino Fundamental 2 completo e Ensino Médio completo, ou seja, entre 9 e 11 anos de estudo. 13\% possuem menos de 5 anos de estudo e $16 \%$ da população tem educação acima do Ensino Médio completo (12 anos de estudo ou mais).

O indivíduo médio entre as mulheres com menos de 5 anos de estudo (Ensino Fundamental 1 incompleto), possui alíquota necessária de 33\% considerando que são contribuintes durante todo seu período ativo. 
Tabela 4 - Alíquotas que equilibram o sistema para $\pi=100 \%$ (contribuição em todos os anos)

\begin{tabular}{|c|c|c|c|c|c|c|c|c|c|c|}
\hline & \multicolumn{2}{|c|}{ Até EF1 } & \multicolumn{2}{|c|}{$\begin{array}{c}\text { EF1 até EF2 } \\
\text { completo }\end{array}$} & \multicolumn{2}{|c|}{$\begin{array}{l}\text { EF2 até EM } \\
\text { completo }\end{array}$} & \multicolumn{2}{|c|}{$\begin{array}{l}\text { Acima de EM } \\
\text { completo }\end{array}$} & \multicolumn{2}{|c|}{ Rural } \\
\hline & $\begin{array}{l}\text { Mulher } \\
\text { (1) }\end{array}$ & $\begin{array}{c}\text { Homem } \\
(2)\end{array}$ & $\begin{array}{l}\text { Mulher } \\
\text { (3) }\end{array}$ & $\begin{array}{c}\text { Homem } \\
(4)\end{array}$ & $\begin{array}{l}\text { Mulher } \\
\text { (5) }\end{array}$ & $\begin{array}{l}\text { Homem } \\
(6)\end{array}$ & $\begin{array}{l}\text { Mulher } \\
(7)\end{array}$ & $\begin{array}{c}\text { Homem } \\
(8)\end{array}$ & $\begin{array}{c}\text { Mulher } \\
(9)\end{array}$ & $\begin{array}{c}\text { Homem } \\
(10)\end{array}$ \\
\hline Pr. Contribuição $(\pi)$ & $100 \%$ & $100 \%$ & $100 \%$ & $100 \%$ & $100 \%$ & $100 \%$ & $100 \%$ & $100 \%$ & $100 \%$ & $100 \%$ \\
\hline Taxa de Cresc. Salarial $(g)$ & $0.18 \%$ & $0.98 \%$ & $1.10 \%$ & $2.21 \%$ & $1.45 \%$ & $2.55 \%$ & $1.95 \%$ & $2.71 \%$ & $0.71 \%$ & $0.95 \%$ \\
\hline Idade Inicial $\left(I_{0}\right)$ & 16.70 & 16.00 & 16.53 & 16.00 & 16.78 & 16.10 & 18.01 & 17.75 & 16.00 & 16.00 \\
\hline Idade de Aposentadoria & 65.0 & 65.0 & 65.0 & 65.0 & 65.0 & 65.0 & 65.0 & 65.0 & 65.0 & 65.0 \\
\hline Tempo de Contrib. $(T \pi)$ & 46.5 & 47.1 & 46.7 & 47.1 & 46.4 & 47.0 & 45.2 & 45.3 & 46.3 & 46.7 \\
\hline \% População & $5.9 \%$ & $6.9 \%$ & $10.3 \%$ & $11.2 \%$ & $18.8 \%$ & $16.6 \%$ & $8.9 \%$ & $6.6 \%$ & $7.1 \%$ & $7.5 \%$ \\
\hline \multicolumn{11}{|l|}{$h=1 \%$} \\
\hline$\alpha$ & 0.33 & 0.28 & 0.28 & 0.29 & 0.28 & 0.29 & 0.29 & 0.30 & 0.29 & 0.28 \\
\hline Taxa de Reposição & 0.83 & 0.64 & 0.62 & 0.51 & 0.58 & 0.48 & 0.53 & 0.47 & 0.67 & 0.64 \\
\hline \multicolumn{11}{|l|}{$h=2 \%$} \\
\hline$\alpha$ & 0.33 & 0.25 & 0.25 & 0.22 & 0.24 & 0.22 & 0.22 & 0.23 & 0.26 & 0.24 \\
\hline Taxa de Reposição & 0.83 & 0.53 & 0.52 & 0.43 & 0.49 & 0.40 & 0.45 & 0.40 & 0.55 & 0.53 \\
\hline \multicolumn{11}{|l|}{$h=3 \%$} \\
\hline$\alpha$ & 0.33 & 0.23 & 0.25 & 0.21 & 0.22 & 0.20 & 0.17 & 0.18 & 0.26 & 0.22 \\
\hline Taxa de Reposição & 0.83 & 0.48 & 0.51 & 0.37 & 0.41 & 0.35 & 0.38 & 0.34 & 0.55 & 0.45 \\
\hline
\end{tabular}

Nota: os valores em negrito representam casos em que o indivíduo recebe o valor do salário mínimo como benefício desde o início do período de aposentadoria.

Para um homem que possui 12 anos ou mais de estudo (Acima de Ensino Médio completo), sua alíquota necessária seria de $30 \%$ para $k=0$, sendo $h=1 \%$. Considerando o cenário em que a taxa de crescimento da economia é de $2 \%$, a alíquota estimada foi de $23 \%$, valor inferior à alíquota praticada atualmente pela Previdência Social. Quando $h=3 \%$, esse grupo possui alíquota de 18\%, considerando que os benefícios são reajustados apenas pela inflação. É interessante observar que as alíquotas necessárias diminuem à medida em que aumenta a taxa de crescimento da economia, e são menores nos casos em que $k=0$, ou seja, nas situações em que os benefícios não sofrem reajuste real.

A Tabela 5 apresenta a situação em que os indivíduos contribuem o tempo mínimo necessário para se aposentar (25 anos). Nesse caso, o valor de $\pi$, a probabilidade de os indivíduos contribuírem para a previdência, é determinado pelo tempo de contribuição. Os valores das alíquotas necessárias sofrem expressivo aumento em comparação com a Tabela 4, dado que nessa 
situação os indivíduos contribuem apenas entre 53\% e 55\% do tempo em que permanecem no mercado de trabalho.

Tabela 5 - Alíquotas que equilibram o sistema para o tempo de contribuição de 25 anos

\begin{tabular}{|c|c|c|c|c|c|c|c|c|c|c|}
\hline & \multicolumn{2}{|c|}{ Até EF1 } & \multicolumn{2}{|c|}{$\begin{array}{c}\text { EF1 até EF2 } \\
\text { completo }\end{array}$} & \multicolumn{2}{|c|}{$\begin{array}{l}\text { EF2 até EM } \\
\text { completo }\end{array}$} & \multicolumn{2}{|c|}{$\begin{array}{l}\text { Acima de EM } \\
\text { completo }\end{array}$} & \multicolumn{2}{|c|}{ Rural } \\
\hline & $\begin{array}{c}\text { Mulher } \\
\text { (1) }\end{array}$ & $\begin{array}{c}\text { Homem } \\
\text { (2) }\end{array}$ & $\begin{array}{l}\text { Mulher } \\
\text { (3) }\end{array}$ & $\begin{array}{c}\text { Homem } \\
\text { (4) }\end{array}$ & $\begin{array}{l}\text { Mulher } \\
(5)\end{array}$ & $\begin{array}{c}\text { Homem } \\
\text { (6) }\end{array}$ & $\begin{array}{c}\text { Mulher } \\
(7)\end{array}$ & $\begin{array}{c}\text { Homem } \\
\text { (8) }\end{array}$ & $\begin{array}{c}\text { Mulher } \\
\text { (9) }\end{array}$ & $\begin{array}{c}\text { Homem } \\
(10)\end{array}$ \\
\hline Pr. Contribuição $(\pi)$ & $53.7 \%$ & $53.1 \%$ & $53.5 \%$ & $53.1 \%$ & $53.8 \%$ & $53.2 \%$ & $55.3 \%$ & $55.2 \%$ & $54.0 \%$ & $53.5 \%$ \\
\hline Taxa de Cresc. Salarial $(g)$ & $0.18 \%$ & $0.98 \%$ & $1.10 \%$ & $2.21 \%$ & $1.45 \%$ & $2.55 \%$ & $1.95 \%$ & $2.71 \%$ & $0.71 \%$ & $0.95 \%$ \\
\hline Idade Inicial $\left(I_{0}\right)$ & 16.70 & 16.00 & 16.53 & 16.00 & 16.78 & 16.10 & 18.01 & 17.75 & 16.00 & 16.00 \\
\hline Idade de Aposentadoria & 65.0 & 65.0 & 65.0 & 65.0 & 65.0 & 65.0 & 65.0 & 65.0 & 65.0 & 65.0 \\
\hline Tempo de Contrib. $(T \pi)$ & 25.0 & 25.0 & 25.0 & 25.0 & 25.0 & 25.0 & 25.0 & 25.0 & 25.0 & 25.0 \\
\hline \% População & $5.9 \%$ & $6.9 \%$ & $10.3 \%$ & $11.2 \%$ & $18.8 \%$ & $16.6 \%$ & $8.9 \%$ & $6.6 \%$ & $7.1 \%$ & $7.5 \%$ \\
\hline \multicolumn{11}{|l|}{$h=1 \%$} \\
\hline$\alpha$ & 0.61 & 0.45 & 0.46 & 0.43 & 0.41 & 0.43 & 0.41 & 0.43 & 0.48 & 0.41 \\
\hline Taxa de Reposição & 0.83 & 0.49 & 0.51 & 0.39 & 0.45 & 0.37 & 0.42 & 0.37 & 0.55 & 0.50 \\
\hline \multicolumn{11}{|l|}{$h=2 \%$} \\
\hline$\alpha$ & 0.61 & 0.44 & 0.46 & 0.37 & 0.37 & 0.33 & 0.31 & 0.33 & 0.48 & 0.38 \\
\hline Taxa de Reposição & 0.83 & 0.48 & 0.51 & 0.33 & 0.38 & 0.31 & 0.35 & 0.31 & 0.55 & 0.41 \\
\hline \multicolumn{11}{|l|}{$h=3 \%$} \\
\hline$\alpha$ & 0.61 & 0.44 & 0.46 & 0.34 & 0.37 & 0.33 & 0.28 & 0.26 & 0.48 & 0.36 \\
\hline Taxa de Reposição & 0.83 & 0.48 & 0.51 & 0.28 & 0.38 & 0.27 & 0.30 & 0.27 & 0.55 & 0.39 \\
\hline
\end{tabular}

Nota: os valores em negrito representam casos em que o indivíduo recebe o valor do salário mínimo como benefício desde o início do período de aposentadoria.

A Tabela 6 apresenta os valores de $\pi$ observados nas PNADs. Esses valores são estimativas do tempo de contribuição dos indivíduos médios de cada um dos grupos. Onde as alíquotas necessárias foram substituídas por traço, os trabalhadores representativos não obteriam o tempo mínimo exigido para aposentadoria, de acordo com a proposta de Reforma da Previdência, de 25 anos. É importante ressaltar que os indivíduos podem entrar com pedido de aposentadoria com idades superiores aos 65 anos. Dessa forma, os indivíduos médios, por exemplo, poderiam permanecer no mercado de trabalho por mais alguns anos e obter os 25 anos exigidos como contribuintes para então receber benefícios de aposentadoria, como no caso dos agentes representativos apresentados nas colunas (7) e (8) da Tabela 3. 
Entretanto, dada as probabilidades de contribuição, isso ocorreria com idades bastante avançadas, à exceção dos homens Ensino Fundamental 2 (completo ou incompleto).

Os trabalhadores menos escolarizados e rurais não se aposentariam pela previdência social e possivelmente teriam seus benefícios pagos pela assistência social. Para aqueles que não conseguirão se aposentar por não obter o tempo mínimo de contribuição, a alíquota de equilíbrio é zero. Por sua vez, o homem médio com escolaridade acima de Ensino Médio completo tem alíquota necessária de $26 \%$, quando $h=1 \%$ e $k=0$. A mulher média, sob as mesmas condições de crescimento econômico, escolaridade e crescimento dos benefícios tem alíquota necessária de 25\%.

Tabela 6 - Alíquotas que equilibram o sistema para tempo de contribuição estimado nas PNADs

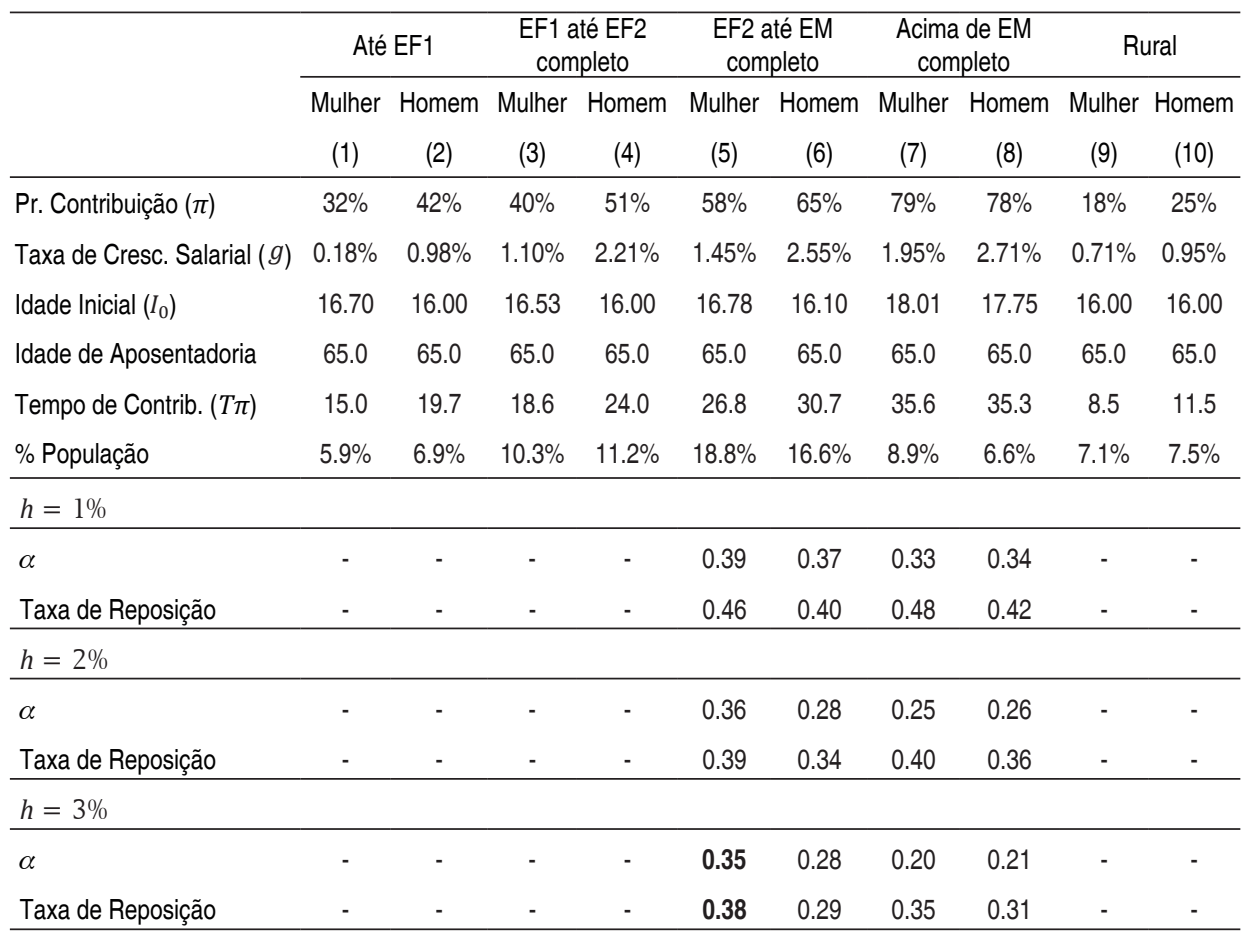

Nota: os valores em negrito representam casos em que o indivíduo recebe o valor do salário mínimo como benefício desde o início do período de aposentadoria. As células sem valores representam casos em que o indivíduo médio não atinge o tempo mínimo de contribuição para se aposentar aos 65 anos. 


\subsubsection{Informalidade}

Os exercícios das seções anteriores tomam como dado o tempo de contribuição e estimam as alíquotas necessárias para o equilíbrio financeiro em função dos parâmetros da reforma Temer. A fim de se ter um ideia da sensibilidade do equilibrio financeiro em relação ao grau de informalidade da economia, apresentamos o mesmo modelo com um exercício distinto: mantendo a alíquota de contribuição da proposta Temer de $28 \%$ e a taxa de juros de $h+n$, encontramos o percentual do período de atividade no mercado de trabalho em que o indivíduo contribui para a previdência $(\pi)$ que é necessário para equilibrar o sistema.

A Tabela 7 abaixo apresenta os resultados para o agente representativo e para os grupos de sexo, escolaridade e tipo de trabalhador separadamente. Os resultado são apresentados para os valores de taxa de cresimento da produtividade $h$ de $1 \%, 2 \%$ e $3 \%$.

Os resultados indicam que para o agente representativo, por exemplo, considerando $h=2 \%$, as mulheres devem ser contribuintes por $73,5 \%$ do tempo (coluna (9)), enquanto que para os homens esse percentual fica em $63,2 \%$ (coluna (10)). A probabilidade comparativamente mais elevada para mulheres ocorre, nesse caso, porque elas recebem o salário mínimo em parte do perído de aposentadoria. A Tabela 7 também explicita que para os indivíduos médios com mais de 11 anos de estudo (colunas (7) e (8)), é necessário contribuir por $66,1 \%$ do tempo para as mulheres e $71 \%$ para os homens para equilibrar o sistema, considerando a taxa de crescimento da economia de $2 \%$. Além disso, os resultados com percentuais acima de $100 \%$ demonstram que para os indivíduos médios de alguns grupos, como as mulheres com menos de 4 anos de estudo (até Ensino Fundamental 1), não há tempo de contribuição suficiente para equilibrar o sistema. Esse cenário também ocorre para quase todos os grupos, supondo uma taxa de crescimento da economia de $1 \%$. 
Tabela 7 - Valores da probabilidade de contribuição $(\pi)$ que equilibram o sistema

\begin{tabular}{|c|c|c|c|c|c|c|c|c|c|c|c|c|}
\hline & \multicolumn{2}{|c|}{ Até EF1 } & \multicolumn{2}{|c|}{$\begin{array}{c}\text { EF1 até EF2 } \\
\text { completo }\end{array}$} & \multicolumn{2}{|c|}{$\begin{array}{c}\text { EF2 até EM } \\
\text { completo }\end{array}$} & \multicolumn{2}{|c|}{$\begin{array}{c}\text { Acima de EM } \\
\text { completo }\end{array}$} & \multicolumn{2}{|c|}{ Rural } & \multicolumn{2}{|c|}{$\begin{array}{c}\text { Agente } \\
\text { Representativo }\end{array}$} \\
\hline & Mulher & Homem & Mulher & Homem & Mulher & Homem & Mulher & Homem & Mulher & & Mulher & Homem \\
\hline & (1) & (2) & (3) & (4) & (5) & (6) & (7) & (8) & (9) & (10) & (9) & (10) \\
\hline $\begin{array}{l}\text { Alíquota de } \\
\text { Contr. }(\alpha)\end{array}$ & $28 \%$ & $28 \%$ & $28 \%$ & $28 \%$ & $28 \%$ & $28 \%$ & $28 \%$ & $28 \%$ & $28 \%$ & $28 \%$ & $28 \%$ & $28 \%$ \\
\hline $\begin{array}{l}\text { Taxa de Cresc. } \\
\text { Salarial }(g)\end{array}$ & $0.18 \%$ & $0.98 \%$ & $1.10 \%$ & $2.21 \%$ & $1.45 \%$ & $2.55 \%$ & $1.95 \%$ & $2.71 \%$ & $0.71 \%$ & $0.95 \%$ & $1.14 \%$ & $1.81 \%$ \\
\hline Idade Inicial $\left(I_{0}\right)$ & 16.70 & 16.00 & 16.53 & 16.00 & 16.78 & 16.10 & 18.01 & 17.75 & 16.00 & 16.00 & 16.99 & 16.00 \\
\hline \% População & $5.9 \%$ & $6.9 \%$ & $10.3 \%$ & $11.2 \%$ & $18.8 \%$ & $16.6 \%$ & $8.9 \%$ & $6.6 \%$ & $7.1 \%$ & $7.5 \%$ & $51.1 \%$ & $48.9 \%$ \\
\hline$\pi(h=1 \%)$ & $118.0 \%$ & $97.8 \%$ & $100.5 \%$ & $109.0 \%$ & $98.9 \%$ & $108.4 \%$ & $105.7 \%$ & $113.8 \%$ & $105.4 \%$ & $101.7 \%$ & $98.0 \%$ & $103.3 \%$ \\
\hline$\pi(h=2 \%)$ & $118.0 \%$ & $83.7 \%$ & $88.6 \%$ & $75.4 \%$ & $75.6 \%$ & $67.0 \%$ & $66.1 \%$ & $71.0 \%$ & $92.6 \%$ & $76.5 \%$ & $73.5 \%$ & $63.2 \%$ \\
\hline$\pi(h=1 \%)$ & $118.0 \%$ & $83.7 \%$ & $88.6 \%$ & $62.6 \%$ & $71.6 \%$ & $62.7 \%$ & $56.5 \%$ & $48.9 \%$ & $92.6 \%$ & $68.8 \%$ & $61.4 \%$ & $59.0 \%$ \\
\hline
\end{tabular}

Nota: os valores em negrito representam casos em que o indivíduo recebe o valor do salário mínimo como benefício desde o início do período de aposentadoria.

\subsection{Justiça Atuarial}

Um sistema previdenciário é atuarialmente justo se o valor presente das contribuições esperadas é igual ao valor presente dos benefícios esperados. Como discutido no Apêndice I, no caso em que a taxa de juros é igual à soma da taxa de crescimento da produtividade e da taxa de crescimento populacional $(r=h+n)$, o sistema é equilibrado financeiramente e justo atuarialmente. Contudo, essa igualdade não está sempre garantida. Quando $r>h+n$ o valor presente das contribuições é maior que o valor presente dos benefícios. O inverso ocorre se $r<h+n$. Assim, o valor da taxa de juros é determinante para a justiça atuarial.

A fim de avaliar a justiça atuarial do sistema previdência da proposta Temer, fazemos o seguinte exercício. Consideramos a alíquota de contribuição de $28 \%$, e para dados tempo de contribuição $T$ e tempo de benefício $F$, calculamos qual a taxa de juros $(r)$ que iguala em valor presente os fluxos de contribuições e benefícios esperados. Em outras palavras, estimamos a taxa interna de retorno do sistema. Esse exercício é feito tanto para o agente representativo quanto para grupos sociodemográficos separadamente. 
A Tabela 8 abaixo apresenta os resultados da taxa de juros $(r)$ para diferentes taxas de crescimento econômico $h$ (1,2 e 3\% a.a.) para o agente representativo. Novamente os resultados são apresentados para homens e mulheres separadamente e são considerados os três casos quando o tempo de contribuição (i) é toda a vida ativa; (ii) é o mínimo necessário de 25 anos; ou (iii) é o tempo de vida ativa observada na PNAD.

A estimação da taxa de juros para o cenário em que os indivíduos são contribuintes durante todo o período em que permanecem no mercado de trabalho (colunas (1) e (2)) gerou os resultados de 1,64\% e 1,79\% a.a. para o caso de $h=2 \%$, para as mulheres e homens, respectivamente. Considerando que as taxas de crescimento populacional são de $0,587 \%$ e $0,642 \%$ a.a. para mulheres e homens, respectivamente, é interessante observar que os resultados obtidos são inferiores aos valores da soma das taxas de crescimentos da produtividade e da população $(h+n)$.

Considerando a situação em que os indivíduos contribuem exatamente por 25 anos (colunas (3) e (4)), a taxa de juros varia de 2,67\% a 3,97\% a.a. para as mulheres e de $2,84 \%$ a $3,16 \%$ a.a. para os homens, dependendo do cenário de crescimento econômico. Nota-se que os valores de $r$ crescem à medida que $h$ aumenta, ou seja, conforme a taxa de crescimento esperada da economia cresce, a taxa interna de retorno aumenta. Para a probabilidade de contribuição encontrada na PNAD (colunas (5) e (6)), o tempo de contribuição obtido é inferior aos 25 anos exigidos, de forma que os indivíduos em questão não poderiam receber benefícios de aposentadoria. Caso recebessem, a taxa de juros seria maior do que nos casos anteriores, exceto em comparação ao caso em que o agente recebe o salário mínimo (mulheres, quando $h=3 \%$ ). Note que o indivíduo poderia expandir sua permanência no mercado de trabalho além dos 65 anos para atingir os 25 anos de contribuição necessários. Nesse caso, as taxas de retorno seriam ligeiramente inferiores àquelas apresentadas nas duas últimas colunas da Tabela 8. Portanto, podemos concluir que a taxas de retorno dos agentes representativos (de homens e mulheres) estão ao redor de 3\%, que é significativamente inferior à taxa de juros básica que tem vigorado na economia brasileira nas últimas décadas (Omar 2008, Bastos 2017). 
Tabela 8 - Taxa interna de retorno anual (r) para o Agente Representativo

\begin{tabular}{lcccccc}
\hline & \multicolumn{5}{c}{ Agente Representativo } \\
\cline { 2 - 7 } & Mulher & Homem & Mulher & Homem & Mulher & Homem \\
& $(1)$ & $(2)$ & $(3)$ & $(4)$ & $(5)$ & $(6)$ \\
\hline Alíquota de Contr. $(\alpha)$ & $28 \%$ & $28 \%$ & $28 \%$ & $28 \%$ & $28 \%$ & $28 \%$ \\
Taxa de Cresc. Salarial $(g)$ & $1.14 \%$ & $1.81 \%$ & $1.14 \%$ & $1.81 \%$ & $1.14 \%$ & $1.81 \%$ \\
Tempo de Contribuição $(T \pi)$ & 46.23 & 47.06 & 25.00 & 25.00 & 23.62 & 24.05 \\
\% População & $51.1 \%$ & $48.9 \%$ & $51.1 \%$ & $48.9 \%$ & $51.1 \%$ & $48.9 \%$ \\
Prob. Contribuição $(\pi)$ & $100.0 \%$ & $100.0 \%$ & $54.1 \%$ & $53.1 \%$ & $51.1 \%$ & $51.1 \%$ \\
$r(h=1 \%)$ & $1.55 \%$ & $1.69 \%$ & $2.67 \%$ & $2.84 \%$ & $2.72 \%$ & $2.92 \%$ \\
$r(h=2 \%)$ & $1.64 \%$ & $1.79 \%$ & $2.81 \%$ & $3.00 \%$ & $2.86 \%$ & $3.08 \%$ \\
$r(h=3 \%)$ & $1.73 \%$ & $1.89 \%$ & $3.97 \%$ & $3.16 \%$ & $3.02 \%$ & $3.25 \%$ \\
\hline
\end{tabular}

Nota: os valores em negrito representam casos em que o indivíduo recebe o valor do salário mínimo como benefício desde o início do período de aposentadoria.

Os mesmos exercícios são feitos para os grupos sociodemográficos separadamente. Os resultados para o caso de contribuição em todos os anos são apresentados na Tabela 9. Os valores em negrito fazem referência aos casos em que os benefícios são iguais ao salário mínimo desde o início do período de aposentadoria. Nota-se que para o grupo de homens com nível educacional acima do Ensino Médio completo, o valor da taxa de juros é de $1,97 \%$ a.a. para $h=2 \%$ (colunas (7) e (8)). Para a mesma taxa de crescimento econômico, as mulheres com a mesma educação possuem taxa de juros implícita de $1,77 \%$ a.a. Para ambos os casos, o valor da taxa interna de retorno é inferior ao valor de $h+n$. 
Tabela 9 - Taxa interna de retorno anual $(r)$ para $\boldsymbol{\pi}=\mathbf{1 0 0 \%}$ (contribuição em todos os anos)

\begin{tabular}{|c|c|c|c|c|c|c|c|c|c|c|}
\hline & \multicolumn{2}{|c|}{ Até EF1 } & \multicolumn{2}{|c|}{$\begin{array}{c}\text { EF1 até EF2 } \\
\text { completo }\end{array}$} & \multicolumn{2}{|c|}{$\begin{array}{c}\text { EF2 até EM } \\
\text { completo }\end{array}$} & \multicolumn{2}{|c|}{$\begin{array}{c}\text { Acima de EM } \\
\text { completo }\end{array}$} & \multicolumn{2}{|c|}{ Rural } \\
\hline & $\begin{array}{c}\text { Mulher } \\
\text { (1) }\end{array}$ & $\begin{array}{l}\text { Homem } \\
\text { (2) }\end{array}$ & $\begin{array}{c}\text { Mulher } \\
\text { (3) }\end{array}$ & $\begin{array}{c}\text { Homem } \\
\text { (4) }\end{array}$ & $\begin{array}{c}\text { Mulher } \\
\text { (5) }\end{array}$ & $\begin{array}{l}\text { Homem } \\
\text { (6) }\end{array}$ & $\begin{array}{c}\text { Mulher } \\
\text { (7) }\end{array}$ & $\begin{array}{c}\text { Homem } \\
\text { (8) }\end{array}$ & $\begin{array}{l}\text { Mulher } \\
\text { (9) }\end{array}$ & $\begin{array}{c}\text { Homem } \\
(10)\end{array}$ \\
\hline Alíquota de Contr. $(\alpha)$ & $28 \%$ & $28 \%$ & $28 \%$ & $28 \%$ & $28 \%$ & $28 \%$ & $28 \%$ & $28 \%$ & $28 \%$ & $28 \%$ \\
\hline Taxa de Cresc. Salarial $(g)$ & $0.18 \%$ & $0.98 \%$ & $1.10 \%$ & $2.21 \%$ & $1.45 \%$ & $2.55 \%$ & $1.95 \%$ & $2.71 \%$ & $0.71 \%$ & $0.95 \%$ \\
\hline 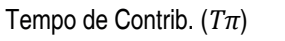 & 46.52 & 47.06 & 46.69 & 47.06 & 46.44 & 46.95 & 45.21 & 45.30 & 46.32 & 46.75 \\
\hline \% População & $5.9 \%$ & $5.9 \%$ & $5.9 \%$ & $6.9 \%$ & $6.9 \%$ & $6.9 \%$ & $10.3 \%$ & $10.3 \%$ & $10.3 \%$ & $11.2 \%$ \\
\hline Prob. Contrib. $(\pi)$ & $100.0 \%$ & $100.0 \%$ & $100.0 \%$ & $100.0 \%$ & $100.0 \%$ & $100.0 \%$ & $100.0 \%$ & $100.0 \%$ & $100.0 \%$ & $100.0 \%$ \\
\hline$r(h=1 \%)$ & $2.06 \%$ & $1.61 \%$ & $1.53 \%$ & $1.78 \%$ & $1.57 \%$ & $1.78 \%$ & $1.68 \%$ & $1.87 \%$ & $1.62 \%$ & $1.67 \%$ \\
\hline$r(h=2 \%)$ & $3.06 \%$ & $2.14 \%$ & $2.22 \%$ & $1.88 \%$ & $1.77 \%$ & $1.88 \%$ & $1.77 \%$ & $1.97 \%$ & $2.36 \%$ & $1.84 \%$ \\
\hline$r(h=3 \%)$ & $4.06 \%$ & $3.11 \%$ & $3.22 \%$ & $2.22 \%$ & $2.55 \%$ & $2.04 \%$ & $1.87 \%$ & $2.07 \%$ & $3.36 \%$ & $2.56 \%$ \\
\hline
\end{tabular}

Nota: os valores em negrito representam casos em que o indivíduo recebe o valor do salário mínimo como benefício desde o início do período de aposentadoria.

A Tabela 10 apresenta os resultados da taxa interna de retorno quando os indivíduos contribuem por 25 anos, o tempo mínimo exigido pela nova regra proposta. Nota-se que, nesse caso, para os indivíduos médios com mais de 11 anos de estudo (acima do Ensino Médio completo), quando $h=2 \%$ os valores de ficam em 2,97\% a.a. para mulheres e 3,19\% a.a. para homens (colunas (7) e (8)). Esses valores obtidos para a taxa de juros são superiores à taxa $h+n$.

Vale destacar que as taxas internas de retorno dos menos escolarizados e dos rurais são, de modo geral, maiores que as dos mais escolarizados, o que indica um caráter redistributivo do sistema proposto, caso todos os trabalhadores contribuíssem por 25 anos. Esse carater redistributivo está associado ao fato de se fixar o salário mínimo como o piso dos benefícios previdenciários. 
Tabela 10 - Taxa interna de retorno anual ( $r$ ) para o tempo de contribuição de 25 anos

\begin{tabular}{|c|c|c|c|c|c|c|c|c|c|c|}
\hline & \multicolumn{2}{|c|}{ Até EF1 } & \multicolumn{2}{|c|}{$\begin{array}{c}\text { EF1 até EF2 } \\
\text { completo }\end{array}$} & \multicolumn{2}{|c|}{$\begin{array}{c}\text { EF2 até EM } \\
\text { completo }\end{array}$} & \multicolumn{2}{|c|}{$\begin{array}{c}\text { Acima de EM } \\
\text { completo }\end{array}$} & \multicolumn{2}{|c|}{ Rural } \\
\hline & $\begin{array}{c}\text { Mulher } \\
\text { (1) }\end{array}$ & $\begin{array}{l}\text { Homem } \\
\text { (2) }\end{array}$ & $\begin{array}{c}\text { Mulher } \\
\text { (3) }\end{array}$ & $\begin{array}{c}\text { Homem } \\
\text { (4) }\end{array}$ & $\begin{array}{c}\text { Mulher } \\
\text { (5) }\end{array}$ & $\begin{array}{c}\text { Homem } \\
(6)\end{array}$ & $\begin{array}{c}\text { Mulher } \\
\text { (7) }\end{array}$ & $\begin{array}{c}\text { Homem } \\
\text { (8) }\end{array}$ & $\begin{array}{l}\text { Mulher } \\
\text { (9) }\end{array}$ & $\begin{array}{c}\text { Homem } \\
(10)\end{array}$ \\
\hline Alíquota de Contr. $(\alpha)$ & $28 \%$ & $28 \%$ & $28 \%$ & $28 \%$ & $28 \%$ & $28 \%$ & $28 \%$ & $28 \%$ & $28 \%$ & $28 \%$ \\
\hline Taxa de Cresc. Salarial $(g)$ & $0.18 \%$ & $0.98 \%$ & $1.10 \%$ & $2.21 \%$ & $1.45 \%$ & $2.55 \%$ & $1.95 \%$ & $2.71 \%$ & $0.71 \%$ & $0.95 \%$ \\
\hline 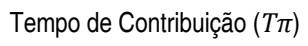 & 25.00 & 25.00 & 25.00 & 25.00 & 25.00 & 25.00 & 25.00 & 25.00 & 25.00 & 25.00 \\
\hline \% População & $5.9 \%$ & $5.9 \%$ & $5.9 \%$ & $6.9 \%$ & $6.9 \%$ & $6.9 \%$ & $10.3 \%$ & $10.3 \%$ & $10.3 \%$ & $11.2 \%$ \\
\hline Prob. Contribuição $(\pi)$ & $53.7 \%$ & $53.1 \%$ & $53.5 \%$ & $53.1 \%$ & $53.8 \%$ & $53.2 \%$ & $55.3 \%$ & $55.2 \%$ & $54.0 \%$ & $53.5 \%$ \\
\hline$r(h=1 \%)$ & $3.77 \%$ & $2.95 \%$ & $3.07 \%$ & $2.94 \%$ & $2.71 \%$ & $2.97 \%$ & $2.82 \%$ & $3.03 \%$ & $3.13 \%$ & $2.76 \%$ \\
\hline$r(h=2 \%)$ & $4.77 \%$ & $3.95 \%$ & $4.07 \%$ & $3.20 \%$ & $3.46 \%$ & $3.13 \%$ & $2.97 \%$ & $3.19 \%$ & $4.13 \%$ & $3.38 \%$ \\
\hline$r(h=3 \%)$ & $5.77 \%$ & $4.95 \%$ & $5.07 \%$ & $3.95 \%$ & $4.46 \%$ & $3.65 \%$ & $3.19 \%$ & $3.35 \%$ & $5.13 \%$ & $4.37 \%$ \\
\hline
\end{tabular}

Nota: os valores em negrito representam casos em que o indivíduo recebe o valor do salário mínimo como benefício desde o início do período de aposentadoria.

Por fim, a Tabela 11 apresenta os resultados para o tempo de contribuição estimado pela PNAD, os valores em negrito, mais uma vez, referem-se às situações em que os benefícios são iguais ao salário mínimo desde o início do período de aposentadoria. As taxas internas de retorno foram calculadas admitindo que o trabalhador se aposenta aos 65 anos. Novamente, os agentes representativos dos trabalhadores urbanos menos escolarizados e dos trabalhadores rurais não conseguiriam obter os 25 anos mínimos de contribuição aos 65 anos de idade e, portanto, não poderiam se aposentar com essa idade. Com exceção dos homens urbanos com Ensino Fundamental 2 (completo e incompleto), expandir o tempo no mercado para obter os 25 anos de contribuição levaria uma aposentadoria com uma idade bastante avançada, fixada as probabilidades de contribuição. 
Tabela 11 - Taxa interna de retorno anual ( $r$ ) para tempo de contribuição estimado nas PNADs

\begin{tabular}{|c|c|c|c|c|c|c|c|c|c|c|}
\hline & \multicolumn{2}{|c|}{ Até EF1 } & \multicolumn{2}{|c|}{$\begin{array}{c}\text { EF1 até EF2 } \\
\text { completo }\end{array}$} & \multicolumn{2}{|c|}{$\begin{array}{c}\text { EF2 até EM } \\
\text { completo }\end{array}$} & \multicolumn{2}{|c|}{$\begin{array}{c}\text { Acima de EM } \\
\text { completo }\end{array}$} & \multicolumn{2}{|c|}{ Rural } \\
\hline & $\begin{array}{c}\text { Mulher } \\
\text { (1) }\end{array}$ & $\begin{array}{c}\text { Homem } \\
\text { (2) }\end{array}$ & $\begin{array}{c}\text { Mulher } \\
\text { (3) }\end{array}$ & $\begin{array}{c}\text { Homem } \\
\text { (4) }\end{array}$ & $\begin{array}{c}\text { Mulher } \\
(5)\end{array}$ & $\begin{array}{c}\text { Homem } \\
\text { (6) }\end{array}$ & $\begin{array}{c}\text { Mulher } \\
\text { (7) }\end{array}$ & $\begin{array}{c}\text { Homem } \\
\text { (8) }\end{array}$ & $\begin{array}{c}\text { Mulher } \\
\text { (9) }\end{array}$ & $\begin{array}{l}\text { Homem } \\
\text { (10) }\end{array}$ \\
\hline Alíquota de Contr. (a) & $28 \%$ & $28 \%$ & $28 \%$ & $28 \%$ & $28 \%$ & $28 \%$ & $28 \%$ & $28 \%$ & $28 \%$ & $28 \%$ \\
\hline Taxa de Cresc. Salarial (g) & $0,18 \%$ & $0,98 \%$ & $1,10 \%$ & $2,21 \%$ & $1,45 \%$ & $2,55 \%$ & $1,95 \%$ & $2,71 \%$ & $0,71 \%$ & $0,95 \%$ \\
\hline Tempo de Contribuição (T $\pi$ ) & 14,95 & 19,67 & 18,58 & 23,97 & 26,77 & 30,71 & 35,57 & 35,33 & 8,46 & 11,54 \\
\hline \% População & $5,9 \%$ & $5,9 \%$ & $5,9 \%$ & $6,9 \%$ & $6,9 \%$ & $6,9 \%$ & $10,3 \%$ & $10,3 \%$ & $10,3 \%$ & $11,2 \%$ \\
\hline Prob. Contribuição $(\pi)$ & $32,1 \%$ & $41,8 \%$ & $39,8 \%$ & $50,9 \%$ & $57,6 \%$ & $65,4 \%$ & $78,7 \%$ & $78,0 \%$ & $18,3 \%$ & $24,7 \%$ \\
\hline$r(h=1 \%)$ & $5,11 \%$ & $3,61 \%$ & $3,90 \%$ & $3,03 \%$ & $2,57 \%$ & $2,55 \%$ & $2,12 \%$ & $2,32 \%$ & $5,99 \%$ & $4,51 \%$ \\
\hline$r(h=2 \%)$ & $6,11 \%$ & $4,61 \%$ & $4,90 \%$ & $3,30 \%$ & $3,25 \%$ & $2,69 \%$ & $2,23 \%$ & $2,45 \%$ & $6,99 \%$ & $5,49 \%$ \\
\hline$r(h=3 \%)$ & $7,11 \%$ & $5,61 \%$ & $5,90 \%$ & $4,07 \%$ & $4,25 \%$ & $3,09 \%$ & $2,36 \%$ & $2,58 \%$ & $7,99 \%$ & $6,49 \%$ \\
\hline
\end{tabular}

Nota: os valores em negrito representam casos em que o indivíduo recebe o valor do salário mínimo como benefício desde o início do período de aposentadoria.

Para os trabalhadores urbanos representativos com ensino médio (completo e incompleto) e ensino superior (completo e incompleto) as taxas interna de retorno foram quase sempre menores que 3\%, independentemente do valor do crescimento da produtividade. Esse resultado mostra que para esses trabalhadores a previdência pública possui um retorno significativamente inferior à taxas de juros reais vigentes na economia (Bastos 2017)

\section{Conclusões}

Este artigo analisa a proposta original de reforma da previdência social no Brasil feita pelo governo Temer, a PEC 287/2016. Nossa principal contribuição é de que investigamos a sustentabilidade financeira do sistema proposto, examinando conjuntamente o critério da justiça atuarial. Por sustentabilidade ou equilíbrio financeiro entende-se o equilíbrio entre os valores das contribuições dos ativos e as despesas com benefícios dos inativos. A justiça atuarial é definida pela igualdade entre o valor presente das contribuições esperadas e o valor presente dos benefícios esperados. 
Num sistema de repartição simples, a taxa de retorno, para dados tempos de atividade $T$ e inatividade $F$, é dada pela soma da taxa de crescimento da produtividade $h$ e a taxa de crescimento populacional $n$. Se a taxa de juros de longo prazo da economia $r$ for igual à soma da taxa de crescimento da produtividade e a taxa de crescimento populacional $(r=h+n)$, o sistema será não apenas equilibrado financeiramente, mas também atuarialmente justo.

Para investigar esses dois aspectos da proposta de reforma, desenvolvemos um modelo em que as pessoas começam a trabalhar, contribuem para a previdência por um período de tempo enquanto trabalham e se aposentam com 65 anos. A idade de entrada no mercado de trabalho e a proporção de tempo que os agentes contribuem são estimadas usando as pesquisas domiciliares do IBGE (PNADs). Levamos em conta as pensões e a probabilidade de aposentadoria por invalidez.

Verificamos, no geral, que a sustentabilidade financeira do novo sistema é muito sensível ao crescimento da produtividade da economia e do grau de formalização da economia. As alíquotas podem variar de $19 \%$ a $28 \%$, no cenário em que o agente representativo contribui durante todo o período de trabalho. Vimos também que os cálculos para o agente representativo escondem muitas diferenças entre os grupos sociodemográficos.

Nosso primeiro resultado substantivo é de que para o agente representativo, alíquotas de $28 \%$ não seriam financeiramente sustentáveis em vários dos cenários estudados, especialmente naquele em que os indivíduos contribuem efetivamente durante 25 anos e ajustam a probabilidade de contribuir para a previdência para se aposentarem aos 65 anos. Afonso (2018) mostra que se implementada, a reforma contida na PEC 287/2016 levaria a uma economia significativa de recursos, da ordem de $\mathrm{R} \$ 1,3$ trilhão até 2038. Nosso resultado indica que, apesar dessa economia, o sistema provavelmente não se sustentaria sob o critério de justiça atuarial.

Nossos resultados para indivíduos médios de diferentes perfis socioeconômicos não trazem evidências que justifiquem uma idade mínima menor para mulheres, para 62 anos, como proposta em mudanças da PEC. ${ }^{22}$ As simulações com idades de aposentadorias comparáveis entre homens e mulheres mostram que, na maioria delas, as mulheres acabam recebendo

${ }^{22}$ Como coloca o Substitutivo de 18 de abril de 2017, elaborado pela Comissão Especial Destinada a Proferir Parecer à Proposta de Emenda Constitucional nº 287-A, de 2016. 
como benefício o piso salarial desde o início do período de aposentadoria, ou em algum momento antes do período final. Isso faz com que as alíquotas para as mulheres sejam maiores do que para os homens. Nesse contexto, reduzir a idade mínima para mulheres elevaria mais as alíquotas correspondentes, que em sua maioria já estão acima da alíquota proposta de $28 \%$.

Além disso, a proposta Temer mantem o caráter redistributivo do nosso sistema de repartição. Afonso e Fernandes (2005) analisam o fluxo de contribuição e benefícios da previdência social ao longo do ciclo de vida para grupos socioeconômicos, e calculam a taxa interna de retorno (TIR) para cada grupo. Eles mostram que as TIRs são significativamente mais elevadas para os grupos mais vulneráveis, além de crescerem para as gerações mais novas. Nossos resultados mostram que sob as regras da PEC 287/2016 essa característica redistributiva seria mantida. Caso colocássemos uma hipótese mais restritiva para a evolução do teto de gastos, como crescimento real nulo, essa característica seria ainda mais acentuada.

Por fim, o fato de uma alíquota de $28 \%$ não ser suficiente para equilibrar o sistema, não significa, necessariamente, que as taxas de retorno do sistema sejam muito elevadas. Considerando o crescimento da produtividade em $2 \%$ e alíquota de contribuição em $28 \%$, a taxa de retorno implícita para o agente representativo é ao redor de 3\% e, portanto, significativamente inferior à média das taxas básicas de juros que vigoraram na economia brasileira nas últimas décadas. Isso significa que os indivíduos médios analisados teriam maior retorno na sua aposentadoria, caso tivessem investido em títulos que pagam as taxas de juros ao invés de pagarem o Sistema de Previdência Social. 


\section{Referências}

Aaron, H. 1966. The Social Insurance paradox. Canadian Journal of Economics and Political Science 32(3): 371-374.

Afonso, L. E. 2018. Reforma Temer: os impactos da PEC nº 287/2016 sobre o RGPS. In Desafios da Nação: artigos de apoio, organizado por João Alberto De Negri, Bruno César Araújo e Ricardo Bacelette, 253-284. Brasília: IPEA 2.

Afonso, L. E. e Fernandes, R. 2005. Uma estimativa dos aspectos distributivos da previdência social no Brasil. Revista Brasileira de Economia 59 (3): 295-334.

Afonso, L.E., Zylberstajn, H. e Souza, A.P. 2006. Mudanças na Previdência Social: Uma Avaliação dos Efeitos de Reformas Paramétricas no RGPS. Economia, Selecta 7(4): 37-69.

Alegretti, L.; Dias, M.; Carvalho, D.; Prado, M.; Cruz, V. 2016. Reforma da Previdência chega ao Congresso nesta Terça, anuncia Temer. Folha de S. Paulo, 05 dez. Mercado.

Andrade, E. I. G. 2001. Envelhecimento e Previdência Social no Brasil. In O Envelhecimento da População Brasileira e o Aumento da Longevidade: subsídios para políticas orientadas ao bem estar do idoso, organizado por Laura L. Rodríguez Wong, 165-188. Belo Horizonte: UFMG/Cedeplar, ABEP.

Beltrão, K. I.; Camanarano, A. A. e Kanso, S. 2004. Dinâmica Populacional Brasileira na Virada do Século XX. IPEA, Texto para Discussão 1034, Rio de Janeiro.

Bastos, E. K. X. 2017. Taxa Neutra de Juros e Expectativas para Inflação e Juros. Carta de Conjuntura 37 (4 Trimestre).

Benites, A. e Mendonça, H. 2017. Por Resistência no Congresso, Temer Recua de Novo na Reforma da Previdência. El País, 06 abr. Brasil.

Blanchard, O. J. e Fischer, S. 1989. Lectures on macroeconomics. Cambridge, Massachusetts: The MIT Press.

Brasil. 2017a. Meirelles: reforma da Previdência terá efeito imediato nas contas públicas. Planalto, 11 mai., Equilíbrio Fiscal. Disponível online: < http://www.brasil.gov.br/noticias/emprego-e-previdencia/2017/05/ meirelles-reforma-da-previdencia-tera-efeito-imediato-nas-contas-publicas $>$

2017b. Presidência da República. Para líder do Governo, Reformas Vão Garantir Retomada do Crescimento. Planalto, 21 mar., Crescimento Econômico. Disponível online: < http://www2.planalto.gov.br/ acompanhe-planalto/releases/2017/03/para-lider-do-governo-reformas-vao-garantir-retomada-do-crescimento $>$

Camarano, A. A. 2002. Envelhecimento da População Brasileira: uma contribuição demográfica. IPEA, Texto para Discussão no. 858, Rio de Janeiro.

Cavalcante, L. R. e De Negri, F. 2014. Evolução Recente dos Indicadores de Produtividade no Brasil. In: Produtividade no Brasil: desempenho e determinantes, organizado por Fernanda De Negri e Luiz Ricardo Cavalcante, 143-172. Brasília: ABDI, IPEA 1.

Constanzi, R. N. 2017. O Caráter Regressivo das Aposentadorias Precoces e os Impactos do Envelhecimento na Previdência Social no Brasil. Informações FIPE, Fundação Instituto de Pesquisas Econômicas 444: 14-20.

Constanzi, R. N. e Ansiliero, G. 2017. Impacto Fiscal da Demografia na Previdência Social. IPEA, Texto para Discussão 2291, Rio de Janeiro.

Constanzi, R. N.; Amaral, A. D.; Dias, C. R.; Ansiliero, G.; Afonso, L. E. e Sidone, O. J. G. 2018. Reforma da Previdência Social. In: Desafios da Nação: artigos de apoio, organizado por João Alberto De Negri, Bruno César Araújo e Ricardo Bacelette, 129-192. Brasília: IPEA 2.

El País. 2017. Reforma da Previdência e Lei Terceirização Levam Milhares às Ruas para Protestar. El País, 01 abr., Brasil.

Fernandes, R. e Gremaud, A.G. 2003. Regime de previdência dos servidores públicos: equilíbrio financeiro e justiça atuarial. Ministério da Fazenda, ESAF, Texto para discussão 1. 
Fernandes, R. e Narita, R. D. T. 2003. Contribuição ao INSS: equilíbrio financeiro e imposto sobre o trabalho. Ministério da Fazenda, ESAF, Texto para discussão 3.

Giambiagi, F.; Pinto, F. e Rothmuller, L. 2018. Reforma Previdenciária em 2019: Elementos para uma tomada de decisão. Mimeo. Disponível online: < http://web.bndes.gov.br/bib/jspui/handle/1408/15304 >.

Giambiagi, F. e Sidone, O. J.G. 2018. A Reforma da Previdência e o Teto Geral de Previdência Social (RGPS). BNDES, Texto para Discussão 121.

Giambiagi, F. e Tafner, P. 2010. Demografia: a ameaça invisível - O dilema previdenciário que o Brasil se recusa a encarar. Rio de Janeiro: Campus-Elsevier.

Giambiagi, F., Zylberstajn, H., Afonso, L.E., Souza, A. P. e Zylberstajn, E. 2007. Impactos de Reformas Paramétricas na Previdência Social Brasileira: Simulações Alternativas. Pesquisa e Planejamento Econômico 37(2): 175-220.

Goudswaard, K. e Caminada, K. 2015. Social security contributions: economic and public finance considerations. International Social Security Review 68(4): 25-45.

Instituto Brasileiro de Geografia e Estatística (IBGE). 2016. Tábuas Completas de Mortalidade - 2015. Rio de Janeiro. Disponível em: < https://www.ibge.gov.br/estatisticas-novoportal/sociais/populacao/9126-tabuas-completas-de-mortalidade.html?edicao $=9176 \& \mathrm{t}=$ sobre $>$.

Lima, D. V. de; Matias-Pereira, J. 2014. A Dinâmica Demográfica e a Sustentabilidade do Regime Geral de Previdência Social Brasileiro. Revista de Administração Pública 48(4): 847-868.

Lyra, P. de T. e Azevedo, A. 2017. Temer Abandona Texto da PEC da Previdência e Aposta em Reforma mais Enxuta. Correio Braziliense, 08 nov. Política.

Moreira, M. de M. 2001. Envelhecimento da População Brasileira: aspectos gerais. In: O Envelhecimento da População Brasileira e o Aumento da Longevidade: subsídios para políticas orientadas ao bem estar do idoso, organizado por Laura L. Rodríguez Wong, 25-56. Belo Horizonte: UFMG/Cedeplar, ABEP.

Nery, P. F. 2016. Economia Política da Reforma da Previdência. Núcleo de Estudos e Pesquisas/CONLEG/ Senado, Texto para Discussão 207, Brasília.

Omar, J. H. D. 2008. Taxa de Juros: comportamento, determinação e implicações para a economia brasileira. Revista de Economia Contemporânea 12(3): 463-490.

Queiroz, B. L. e Fígoli, M. G. B. 2011. Population Aging and the Cost of Public Pension in Brazil. UFMG, Cedeplar, Texto para Discussão 438, Belo Horizonte.

Queisser, M. e Whitehouse, E. 2006. Neutral or Fair?: Actuarial Concepts and Pension-System Design. OECD Publishing, OECD Social, Employment and Migration Working Papers 40, Paris. http://dx.doi. org/10.1787/351382456457

Sinn, H. 2000. Why a Funded Pension System is Useful and Why It is Not Useful. International Tax and Public Finance (7): 389-410.

Tafner, P. 2011. Previdência no Brasil: um (modesto) passo adiante nas reformas. Mimeo.

Tafner, P. 2012. Desafios e Reformas da Previdência Social Brasileira. Revista USP (93): 137-156.

Turra, Cassio M.; Afonso, L.E. 2017. A consolidação da previdência social desde 1988 e seu futuro em um país em envelhecimento. In: Políticas Públicas no Brasil: Uma Abordagem Institucional, organizado por Gilmar Mendes e Paulo Paiva, 317-350. São Paulo: Saraiva, 1 ed.

Zylberstajn, H., Afonso, L.E. e Souza, A.P. 2006. Social Security reform and Transition Cost: Simulating a Universal System for Brazil. Revista de Contabilidade e Finanças - Especial Atuária 17(2): 56-74.

Zylberstajn, H., Zylberstajn, E. Afonso, L.E. e Souza, A.P. 2010. Uma proposta para a criação de um sistema único de Previdência Social para o Brasil. Revista de Economia e Relações Internacionais 8(16): 126-144. 


\section{Apêndice I - Alíquota de Equilíbrio em um Sistema de Repartição}

Suponha que a primeira geração entra no sistema no instante zero. Para simplificar, admita que a primeira geração tem tamanho um, recebe aposentadoria a partir de $T$ e morre em $F$. A cada instante aparece uma nova geração $(1+n)$ vezes maior do que a geração anterior. $O$ fato de, no período de contribuição, os salários crescerem, por instante de tempo, em decorrência do tempo de serviço (a uma taxa $g$ ) pode ser pensado como um aumento no tamanho da geração ao invés de um aumento de salário. Assim, a geração que ingressou no mercado de trabalho no instante zero com tamanho um, atingirá, no período $T$, o tamanho $e^{g T}$. Os aposentados, no momento da aposentadoria, recebem uma parcela p do salário dos ativos. Caso os benefícios aumentem com a produtividade do sistema, a razão benefício/salário é fixa no tempo. Por outro lado, se os benefícios não forem reajustados, a razão benefício/salário sofrerá um desconto, dado pela taxa de aumento na produtividade.

No início as contribuições crescem e não há benefícios para serem pagos. O superávit orçamentário atingirá seu máximo em $T$, quando a primeira geração se aposenta. O sistema atinge o equilíbrio de longo prazo em $F$, quando a primeira geração sai do sistema. Nesse ponto o número de beneficiários sobre o número de contribuintes e a taxa de reposição salarial $(p)$ determinam a contribuição necessária para manter o volume de contribuições igual ao volume de benefícios. De forma similar ao aumento dos salários por tempo de serviço, podemos pensar que a geração de aposentado se reduz a taxa $h-k(k=0$ ou $h)$.

Quando o sistema atinge a idade $F$, o número de beneficiários é dado por:

$$
N^{B}=\int_{T}^{F} e^{g T} e^{n(F-t)} e^{(k-h)(t-T)} d t
$$

Por sua vez o número de contribuintes seria:

$$
N^{C}=\int_{0}^{T} e^{n(F-t)} e^{g t} d t
$$

A alíquota de contribuição que equilibra o sistema é:

$$
p \frac{N^{B}}{N^{C}}=\frac{p(g-n) e^{(h+g-k) T}}{e^{(g-n) T}-1} \frac{e^{(k-h-n) F}-e^{(k-h-n) T}}{k-h-n}
$$


Note que a equação acima é idêntica a Equação (5), que determina a alíquota atuarialmente justa, quando $\pi=1$. Para conciliar essa expressão com (5) basta considerar que $N^{C}$ é o número de contribuintes em potencial e o número de contribuintes efetivos é $\pi N^{C}$, onde $\pi$ é a probabilidade de um contribuinte em potencial contribuir para a previdência. Ou seja, a probabilidade de ele ser formal.

\section{Apêndice II - Estimações da Equação Minceriana}

Tabela Al - Estatísticas Descritivas para o Total de Ocupados

\begin{tabular}{lcc}
\hline \multicolumn{1}{c}{ Variáveis } & Mulheres & Homens \\
\hline Ln (rendimentos) & 6.7 & 7.0 \\
Rendimentos & 790.4 & 1085.8 \\
Tempo de Serviço & 20.5 & 22.9 \\
Até EF1 & 0.23 & 0.35 \\
EF1 a EF2 completo & 0.21 & 0.25 \\
EF2 a EM completo & 0.36 & 0.29 \\
Acima de EM completo & 0.20 & 0.12 \\
Obs. & $1,180,670$ & $1,772,508$ \\
\hline
\end{tabular}

Fonte: PNAD 1992-2015/IBGE. Elaboração própria. Notas: Rendimentos no trabalho principal, a preços de outubro de 2015, deflacionado pelo Índice Nacional de Preços ao Consumidor (INPC). Amostra de pessoas ocupadas com rendimento positivo no trabalho principal

Tabela A2 - Estatísticas Descritivas para Grupos Socioeconômicos

\begin{tabular}{lccccccccccc}
\hline \multirow{2}{*}{ Variáveis } & \multicolumn{2}{c}{ Até EF1 } & \multicolumn{2}{c}{$\begin{array}{c}\text { EF1 até EF2 } \\
\text { completo }\end{array}$} & \multicolumn{2}{c}{$\begin{array}{c}\text { EF2 até EM } \\
\text { completo }\end{array}$} & \multicolumn{2}{c}{$\begin{array}{c}\text { Acima de EM } \\
\text { completo }\end{array}$} & \multicolumn{2}{c}{ Rural } \\
\cline { 2 - 12 } & Mulher & Homem & Mulher & Homem & Mulher & Homem & Mulher & Homem & Mulher & Homem \\
\hline Ln (Rendimentos) & 6.1 & 6.7 & 6.4 & 6.9 & 6.8 & 7.2 & 7.6 & 8.1 & 5.9 & 6.3 \\
Rendimentos & 458.1 & 796.9 & 608.0 & 1020.2 & 869.7 & 1383.9 & 2002.5 & 3298.7 & 364.9 & 555.8 \\
Tempo de Serviço & 29.4 & 29.5 & 20.5 & 20.1 & 16.3 & 18.0 & 18.3 & 21.0 & 22.7 & 26.5 \\
Até EF1 & 1.00 & 1.00 & 0.00 & 0.00 & 0.00 & 0.00 & 0.00 & 0.00 & 0.49 & 0.69 \\
EF1 a EF2 completo & 0.00 & 0.00 & 1.00 & 1.00 & 0.00 & 0.00 & 0.00 & 0.00 & 0.21 & 0.19 \\
EF2 a EM completo & 0.00 & 0.00 & 0.00 & 0.00 & 1.00 & 1.00 & 0.00 & 0.00 & 0.23 & 0.11 \\
Acima de EM completo & 0.00 & 0.00 & 0.00 & 0.00 & 0.00 & 0.00 & 1.00 & 1.00 & 0.07 & 0.02 \\
Obs. & 231,003 & 431,994 & 231,834 & 403,182 & 400,537 & 477,884 & 229,965 & 200,741 & 88,796 & 258,678 \\
\hline
\end{tabular}

Fonte: PNAD 1992-2015/IBGE. Elaboração própria. Notas: Rendimentos no trabalho principal, a preços de outubro de 2015, deflacionado pelo Índice Nacional de Preços ao Consumidor (INPC). Amostra de pessoas ocupadas com rendimento positivo no trabalho principal 
Tabela A3 - Estimação para o Total de Ocupados

\begin{tabular}{lcc}
\hline \multirow{2}{*}{ Variáveis Independentes } & \multicolumn{2}{c}{ Variável Dependente: Ln (Salário) } \\
\cline { 2 - 3 } & Mulher & Homem \\
\hline Tempo de Serviço & $(1)$ & $(2)$ \\
EF completo & $0.0114^{\star \star *}$ & $0.0181^{\star \star *}$ \\
& $(6.52 \mathrm{e}-05)$ & $(5.02 \mathrm{e}-05)$ \\
EM completo & $0.428^{\star \star *}$ & $0.520^{\star \star *}$ \\
& $(0.00230)$ & $(0.00157)$ \\
ES completo & $0.850^{\star \star *}$ & $0.893^{\star \star *}$ \\
& $(0.00223)$ & $(0.00163)$ \\
Constante & $1.689^{\star \star *}$ & $1.738^{\star \star *}$ \\
& $(0.00251)$ & $(0.00227)$ \\
\hline Observações & $5.548^{\star \star *}$ & $5.948^{\star \star *}$ \\
R-Quadrado & $(0.00491)$ & $(0.00347)$ \\
\hline
\end{tabular}

Fonte: PNAD 1992-2015/IBGE. Elaboração própria. Notas: regressões do Ln dos rendimentos no trabalho principal, a preços de outubro de 2015, deflacionado pelo Índice Nacional de Preços ao Consumidor (INPC). Amostra de pessoas ocupadas com rendimento positivo no trabalho principal. Regressões adicionalmente controladas por variáveis dummy de ano. Erros padrão robustos entre parênteses. Significância: ${ }^{* * *} \mathrm{p}<0.01,{ }^{* *} \mathrm{p}<0.05,{ }^{*} \mathrm{p}<01$.

Tabela A4 - Estimação para Grupos Socioeconômicos

\begin{tabular}{|c|c|c|c|c|c|c|c|c|c|c|}
\hline \multirow{3}{*}{$\begin{array}{l}\text { Variáveis } \\
\text { Indepen- } \\
\text { dentes }\end{array}$} & \multicolumn{10}{|c|}{ Variável Dependente: Ln (Salário) } \\
\hline & \multicolumn{2}{|c|}{ Até EF1 } & \multicolumn{2}{|c|}{ EF1 até EF2 completo } & \multicolumn{2}{|c|}{ EF2 até EM completo } & \multicolumn{2}{|c|}{ Acima de EM completo } & \multicolumn{2}{|c|}{ Rural } \\
\hline & $\begin{array}{l}\text { Mulher } \\
\text { (1) }\end{array}$ & $\begin{array}{l}\text { Homem } \\
\text { (2) }\end{array}$ & $\begin{array}{l}\text { Mulher } \\
\text { (3) }\end{array}$ & $\begin{array}{l}\text { Homem } \\
\text { (4) }\end{array}$ & $\begin{array}{l}\text { Mulher } \\
\text { (5) }\end{array}$ & $\begin{array}{l}\text { Homem } \\
(6)\end{array}$ & $\begin{array}{l}\text { Mulher } \\
\text { (7) }\end{array}$ & $\begin{array}{l}\text { Homem } \\
\text { (8) }\end{array}$ & $\begin{array}{l}\text { Mulher } \\
(9)\end{array}$ & $\begin{array}{c}\text { Homem } \\
(10)\end{array}$ \\
\hline \multirow[t]{2}{*}{$\begin{array}{l}\text { Tempo de } \\
\text { Serviço }\end{array}$} & $0.00181^{\star \star \star}$ & $0.00981^{\star \star *}$ & $0.0110^{\star * \star}$ & $0.0221^{\star \star \star}$ & $0.0145^{\star \star \star}$ & $0.0255^{\star \star \star}$ & $0.0195^{\star * \star}$ & $0.0271^{\star \star \star}$ & $-0.00497^{\star \star \star}$ & $0.00202^{\star * \star}$ \\
\hline & $(0.000137)$ & $(9.21 e-05)$ & $(0.000138)$ & $(9.90 e-05)$ & $(0.000106)$ & $(9.34 \mathrm{e}-05)$ & $(0.000160)$ & $(0.000168)$ & $(0.000253)$ & $(0.000130)$ \\
\hline \multirow[t]{2}{*}{ Constante } & $5.800^{\star \star \star}$ & $6.288^{\star \star *}$ & $6.050^{\star * \star}$ & $6.434^{\star \star \star}$ & $6.496^{\star \star \star}$ & $6.843^{\star \star \star}$ & $7.156^{\star \star \star}$ & $7.562^{\star \star \star}$ & $5.524^{\star * \star}$ & $6.049^{\star * \star}$ \\
\hline & $(0.00851)$ & $(0.00556)$ & $(0.00911)$ & $(0.00603)$ & $(0.00864)$ & $(0.00774)$ & $(0.0117)$ & $(0.0129)$ & $(0.0176)$ & $(0.00869)$ \\
\hline Observações & 231,003 & 431,994 & 231,834 & 403,182 & 400,537 & 477,884 & 229,965 & 200,741 & 88,851 & 258,868 \\
\hline R-Quadrado & 0.043 & 0.057 & 0.072 & 0.158 & 0.075 & 0.179 & 0.076 & 0.142 & 0.065 & 0.033 \\
\hline
\end{tabular}

Fonte: PNAD 1992-2015/IBGE. Elaboração própria. Notas: regressões do Ln dos rendimentos no trabalho principal, a preços de outubro de 2015, deflacionado pelo Indice Nacional de Preços ao Consumidor (INPC). Amostra de pessoas ocupadas com rendimento positivo no trabalho principal. Regressões adicionalmente controladas por variáveis dummy de ano. Erros padrão robustos entre parênteses. Significância: ${ }^{* * *} \mathrm{p}<0.01,{ }^{* *} \mathrm{p}<0.05,{ }^{*} \mathrm{p}<01$. 


\section{Apêndice III - Implementação de Casos em que o Piso da Previdência alcança os Benefícios}

Nesse apêndice, descrevemos o cálculo da alíquota atuarialmente justa e da Taxa de Retorno ao Investimento no caso em que o indivíduo se aposenta recebendo o benefício calculado a partir da média do salário de contribuição (crescendo à taxa $k=0$ ) e, antes do período final, passa a receber o valor do salário mínimo (que cresce à taxa $k=h$ ).

Por definição,

$p=\frac{\tilde{p} \bar{w}}{w_{T}}=\frac{\tilde{p}\left(\frac{1}{T} \int_{0}^{T} w_{0} e^{(g+h) t} d t\right)}{w_{0} e^{(g+h) T}}=\frac{\frac{\tilde{p} w_{0}}{T(g+h)}\left[e^{(g+h) T}-1\right]}{w_{0} e^{(g+h) T}}=\frac{\tilde{p}}{T(g+h)} \frac{\left[e^{(g+h) T}-1\right]}{e^{(g+h) T}}$

Como o piso do benefício das aposentadorias cresce à taxa $h$ e, por hipótese, os benefícios que estão acima do piso crescem à taxa $k=0$, então se os indivíduos vivessem para sempre, em algum momento o piso dos benefícios superaria o benefício recebido. Após o instante $T$, o intervalo $\Delta T$ que decorre até que o salário mínimo supere o benefício será aquele em que a seguinte condição é verdadeira:

$$
S M_{T+\Delta T} \geq p w_{T}
$$

Com a definição de $p$, a condição acima equivale a:

$$
\Delta T \geq \frac{\ln \left(\frac{\tilde{p}}{T(g+h)} \frac{\left[e^{(g+h) T}-1\right]}{e^{(g+h) T}} \frac{w_{T}}{S M_{T}}\right)}{h}
$$

Comparamos então o instante $T+\Delta T$ com o instante final $F$, para saber se aplicaremos o piso do benefício. Caso $T+\Delta T<F$, então para $t \in[T, T+\Delta T]$ o benefício será $p W_{T}$. Para $t \in[T+\Delta T, F]$, o benefício será igual ao piso dos benefícios, $S M_{t}$.

Para os casos em que o salário mínimo alcança o valor do benefício antes do período final, o valor presente do fluxo de benefícios será:

$$
V P_{0}^{b}=\int_{T}^{T+\Delta T} p w_{T} e^{k(t-T)} e^{-r t} d t+\int_{T+\Delta T}^{F} S M_{T+\Delta T} e^{h(t-T)} e^{-r t} d t
$$


Supondo $k=0$ e $r=h+k$, a alíquota atuarialmente justa será:

$$
a=\frac{g-n}{\pi\left[e^{T(g-n)}-1\right]}\left\{p e^{T(g+h)} \frac{\left[e^{-(T+\Delta T)(h+n)}-e^{t(h+n)}\right]}{-(h+n)}+\frac{S M_{0}}{w_{0}} e^{h(\Delta T)} \frac{\left[e^{-F n}-e^{-(T+\Delta T) n}\right]}{-n}\right\}
$$

No exercício em que fixamos a alíquota em $a=0.28$, obtemos a probabilidade de contribuição para balancear contribuições e benefícios a partir da Equação (Al). Utilizando a definição de $p$, isolamos $\pi$, de modo que temos:

$$
\pi=\frac{0.51 A B D+A C}{(1-0.01 T A B D)^{\prime}}
$$

onde, $A \equiv \frac{g-n}{a\left[e^{T(g-n)}-1\right]}, B \equiv e^{T(g+h)} \frac{\left[e^{-(T+\Delta T)(h+n)}-e^{t(h+n)}\right]}{-(h+n)}$,

$$
C \equiv \frac{S M_{0}}{w_{0}} e^{h(\Delta T)} \frac{\left[e^{-F n}-e^{-(T+\Delta T) n}\right]}{-n}, \text { e } D \equiv \frac{\left[e^{(h+g) T}-1\right]}{T(g+h) e^{(h+g) T}}
$$

Para o cálculo da TIR, com $k=0$, temos a partir da equação (Al):

$$
\begin{aligned}
& \pi a w_{0} \frac{\left[e^{T(h+g-r)}-1\right]}{h+g-r}=p w_{0} e^{T(g+h)} \frac{\left[e^{-(T+\Delta T) r}-e^{-T r}\right]}{-r}+S M_{0} \frac{\left[e^{F(h-r)}-e^{(T+\Delta T)(h-r)}\right]}{h-r} \\
& \Rightarrow \pi a \frac{\left[e^{T(h+g-r)}-1\right]}{h+g-r}-p e^{T(g+h)} \frac{\left[e^{-(T+\Delta T) r}-e^{-T r}\right]}{-r}-\frac{S M_{0}}{w_{0}} \frac{\left[e^{F(h-r)}-e^{(T+\Delta T)(h-r)}\right]}{h-r}=0
\end{aligned}
$$

Resolvemos numericamente a equação acima para $r$. 